\title{
Ciglitazone Increases Adiponectin and Adipogenic Gene Expression in Bovine Skeletal Muscle Satellite Cells
}

\author{
Junfang Zhang \\ Yanbian University \\ Yan Yan \\ Yanbian University \\ Jianfu Sun \\ Yanbian University \\ Ying Wang \\ Yanbian University

\section{Yan Cui} \\ Yanbian University

\section{Bin Sun} \\ Yanbian University \\ Jia Yu \\ Chungbuk National University \\ Qiang Li \\ Yanbian University \\ Changguo Yan \\ Yanbian University

\section{S.H. Choi} \\ Chungbuk National University
}

\section{S.B. Smith}

Texas A\&M University College Station

Xiangzi Li ( $\sim$ Ixz@ybu.edu.cn )

Yanbian University https://orcid.org/0000-0003-3061-3847

\section{Research}

Keywords: Bovine Satellite cells, Ciglitazone, Adipogenesis, Myogenesis, Differentially expressed genes

Posted Date: December 17th, 2020

DOI: https://doi.org/10.21203/rs.3.rs-129116/v1 
License: (c) (i) This work is licensed under a Creative Commons Attribution 4.0 International License. Read Full License 
1 Ciglitazone increases adiponectin and adipogenic gene expression in bovine skeletal muscle satellite cells ${ }^{1}$

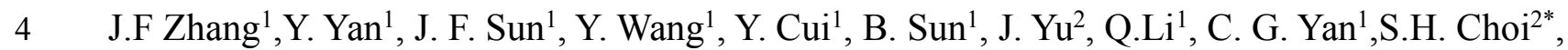

5 S. B. Smith ${ }^{3 *}$, and X. Z. $\mathrm{Li}^{1 *}$

$7 \quad{ }^{1}$ Engineering Research Center of North-East Cold Region Beef Cattle Science \& Technology

8 Innovation, Ministry of Education, Department of Animal Science, Yanbian University,

9 Yanji, 133002, China.

$10{ }^{2}$ Department of Animal Science, Chungbuk National University, Cheongju, Chungbuk 361-763,

11 Republic of Korea.

$12{ }^{3}$ Department of Animal Science, Texas A\&M University, College Station. TX 77843-2471.

13

14 2Corresponding authors: 1xz@ybu.edu.cn; sbsmith@tamu.edu; seonghc@,cbnu.ac.kr

15 Running head: Ciglitazone and bovine satellite cells 


\section{Abstract}

17 Background: Ciglitazone is a member of the thiazolidinedione (TZD) family, and specifically

18 binds to peroxisome proliferator-activated receptor- $\gamma(P P A R \gamma)$, thereby promoting adipocyte

19 differentiation. We hypothesized that ciglitazone as a $P P A R \gamma$ ligand in the absence of an

20 adipocyte differentiation cocktail would increase adiponectin and adipogenic gene expression in

21 bovine satellite cells (BSC).

22 Methods: Muscle-derived bovine satellite cells were isolated from six, 18-month-old Yanbian

23 Yellow Cattle. The BSC were cultured for $96 \mathrm{~h}$ in differentiation medium containing $5 \mu \mathrm{M}$

24 ciglitazone $(\mathrm{CL}), 10 \mu \mathrm{M}$ ciglitazone $(\mathrm{CM})$, or $20 \mu \mathrm{M}$ ciglitazone $(\mathrm{CH})$. Control $(\mathrm{CON}) \mathrm{BSC}$

25 were cultured only in differentiation medium (containing $2 \%$ horse serum).

26 Results: The presence of myogenin, desmin, and paired box 7 ( $\operatorname{Pax} 7)$ proteins were confirmed in

27 the BSC by immunofluorescence staining. The $\mathrm{CL}, \mathrm{CM}$, and $\mathrm{CH}$ treatments produced higher

28 concentrations of triacylglycerol and lipid droplet accumulation in myotubes than those of the

29 CON treatment. Ciglitazone treatments significantly increased the relative expression of $P P A R \gamma$,

$30 \mathrm{CCAAT} /$ enhancer-binding protein alpha $(C / E B P \alpha), C / E B P \beta$, fatty acid synthase stearoyl-CoA

31 desaturase $(S C D)$ and perilipin 2. Ciglitazone treatments increased gene expression of paired box

$323(\operatorname{Pax} 3)$ and $P a x 7$ and decreased expression of myogenic differentiation-1, myogenin, myogenic

33 regulatory factor-5 $(M R F 5)$, and $M Y F 4(\mathrm{P}<0.01)$. Adiponectin concentration caused by

34 ciglitazone treatments was significantly greater than CON $(\mathrm{P}<0.01)$. RNA sequencing showed 
35 that 281 differentially expressed genes (DEGs) were found in the treatments of ciglitazone.

36 DEGs gene ontology (GO) analysis showed that the top 10 GO enrichment significantly changed

37 the biological processes such as protein trimerization, negative regulation of cell proliferation,

38 adipocytes differentiation, and cellular response to external stimulus. KEGG pathway analysis

39 showed that DEGs were involved into p53 signaling pathway, PPAR signaling pathway,

40 biosynthesis of amino acids, TNF signaling pathway, non-alcoholic fatty liver disease (NAFLD),

41 PI3K-Akt signaling pathway, and Wnt signaling pathway.

42 Conclusion: These results indicate that ciglitazone acts as $P P A R \gamma$ agonist, effectively increasing

43 the adiponectin concentration and adipogenic gene expression, and stimulating the conversion of

44 BSC to adipocyte-like cells in the absence of adipocyte differentiation cocktail.

45 Keywords: Bovine Satellite cells, Ciglitazone, Adipogenesis, Myogenesis, Differentially

46 expressed genes 


\section{$47 \quad$ Background}

48 The thiazolidinediones (TZD) family specifically bind to and activate proliferator-activated

49 receptor- $\gamma(P P A R \gamma)$, increase its expression and that of the related genes (e.g.,

50 CCAAT/enhancer-binding protein alpha $(C / E B P \alpha))$, and promote adipocyte differentiation [1].

51 Yeow et al. demonstrated that the TZD rosiglitazone, in the absence of supplemental fatty acids,

52 strongly up-regulated $P P A R \gamma$ expression in $\mathrm{C} 2 \mathrm{C} 12$ cells, and proposed that rosiglitazone

53 inhibited myogenesis [2]. Singh et al. reported that the TZD ciglitazone up-regulated PPAR $\gamma$ and

$54 C / E B P \alpha$ gene expression and depressed myoblast fusion in porcine satellite cells [3]. Our

55 laboratory previously reported that culture of bovine muscle satellite cells (BSC) in medium

56 supplemented with oleic acid (18:1n-9), in the absence or presence of ciglitazone, responded

57 with increases in $P P A R \gamma$ and CCAAT/enhancer-binding protein beta $(C / E B P \beta)$ gene expression

58 in myotubes [4]. Teboul et al. first reported the almost complete conversion of $\mathrm{C} 2 \mathrm{C} 12$ myoblasts

59 to lipid-filled cells when incubated with linoleic acid (18:2n-6) plus the TZD pioglitazone, as

60 indicated by a cessation of myoblast fusion, swelling of myoblasts through lipid filling,

61 down-regulation of myogenin $(M Y O G)$, and up-regulation of adipocyte lipid-binding protein

62 gene expression [5]. In our previous study [4], we established that $10 \mu \mathrm{M}$ ciglitizone

63 down-regulated the expression of genes associated with myogenesis, and up-regulated genes

64 involved in adipogenesis. However, we did not establish that $10 \mu \mathrm{M}$ ciglitizone would elicit

65 maximal effects on adipogenesis and/or myogenesis. Therefore, we hypothesized that greater 
concentration of ciglitazone would more strongly promote the adipocyte phenotype in bovine BSC.

For the current study, we selected a differentiation medium containing DMEM supplemented with $2 \%$ horse serum based on Singh et al. [3], who described the trans-differentiation of porcine satellite cells into adipoblasts. Here, however, we altered the adipogenic mixture of that study (DMEM, horse serum, penicillin/streptomycin, ascorbic acid, biotin, acetic acid, pantothenic acid, dexamethasone, isobutyl ethylxanthine, insulin, and ciglitazone) to include increasing concentrations of ciglitazone $(5,10$, and $20 \mu \mathrm{M})$. We changed the traditional cocktail of differentiation and studied the effect of ciglitazone alone on adipogenic transdifferentiation of BSC without other factors promoting lipid deposition. RNA-seq was used to further analyze and validate the changes of adipogenesis-related genes and pathways after treatment with different concentrations of ciglitazone. We included horse serum in the media to encourage BSC proliferation and myogenic gene expression to better reflect in situ conditions.

\section{Material and methods}

\section{Ethics statement}

All experimental procedures were approved by the Yanbian University Institutional Animal Care and Use Committee.

\section{Bovine satellite cell isolation}


84 The isolation and culture of BSC were performed exactly as described previously [4].

85 Muscle-derived BSC were isolated from six 18-month-old Yanbian Yellow cattles raised at

86 Yanbian University. Using sterile techniques, approximately $800 \mathrm{~g}$ of semimembranous muscle

87 was dissected and transported to the cell culture laboratory within $10 \mathrm{~min}$. Cell isolation procedures were conducted in a sterile environment in a culture hood.

After the removal of connective tissue, the muscles were grounded through a sterile meat grinder. Ground muscles were incubated with $0.1 \%$ pronase (Calbiochem, La Jolla, CA, USA) in

91 Earl's Balanced Salt Solution (Sigma-Aldrich, Louis, MO, USA) for $1 \mathrm{~h}$ at $37^{\circ} \mathrm{C}$ with frequent 92 mixing [6]. After incubation, the mixture was centrifuged at $1,500 \times \mathrm{g}$ for $4 \mathrm{~min}$, the pellets were 93 suspended in phosphate-buffered saline (PBS) (140 mM NaCl, $1 \mathrm{mM} \mathrm{KH}_{2} \mathrm{PO}_{4}, 3 \mathrm{mM} \mathrm{KCl}, 8$ $94 \mathrm{mM} \mathrm{Na} \mathrm{HPO}_{4}$; Gibco Life Technologies, Grand Island, NY), and the suspensions were 95 centrifuged at $500 \times \mathrm{g}$ for $10 \mathrm{~min}$. The supernates were centrifuged at $500 \times \mathrm{g}$ for $10 \mathrm{~min}$ to 96 pellet the mononucleated cells. The PBS wash and differential centrifugation steps were repeated 97 twice. The resulting mononucleated cell preparations were suspended in Dulbecco's modified Eagle medium (DMEM; Gibco) containing 10\% fetal bovine serum (FBS; Gibco), 1× antibiotic-antimycotic (Gibco), and 10\% (vol/vol) dimethyl sulfoxide (Sigma-Aldrich) at $37^{\circ} \mathrm{C}$,

100 before being frozen and stored in liquid nitrogen.

\section{Bovine satellite cells culture}

102 Experiments were replicated in three independent incubations (passage no. 2 of the BSC 
103 obtained from three Yanbian Yellow cattle for all experiments). The BSC were resuspended and

104 maintained in the growth medium composed of DMEM, $10 \% \mathrm{FBS}$, and $1 \%$

105 penicillin/streptomycin at $37^{\circ} \mathrm{C}$ in a humidified atmosphere of $95 \% \mathrm{O}_{2}$ and $5 \% \mathrm{CO}_{2}$. Upon

106 reaching confluence, the growth medium was replaced by the differentiation medium composed

107 of DMEM, $2 \%$ horse serum, and $1 \%$ penicillin/streptomycin.

108 We changed the differentiation components of Singh et al. (2007), omitting ascorbic acid, biotin,

109 acetic acid, panthothenic acid, dexamethasone, isobutylmethylxanthine, and insulin. The BSC

110 were cultured for $96 \mathrm{~h}$ in the differentiation medium containing $5 \mu \mathrm{M}$ ciglitazone (CL), $10 \mu \mathrm{M}$

111 ciglitazone $(\mathrm{CM})$, or $20 \mu \mathrm{M}$ ciglitazone $(\mathrm{CH})$. Control $(\mathrm{CON}) \mathrm{BSC}$ were cultured only in

112 differentiation medium. Ciglitazone (Sigma-Aldrich) was dissolved in ethanol before addition to

113 BSC cultures. Cell size and viability were calculated with a Luna Automated Cell Counter (Logo

114 Biosystems, Annandale, VA) after trypan blue staining.

115 Immunostaining

116 The isolated BSC were cultured to approximately $70 \%$ confluence in DMEM with 10\% FBS and

$1171 \%$ penicillin/streptomycin without ciglitazone. BSC were grown on coverslips for $3 \mathrm{~d}$ and fixed

118 with 4\% paraformaldehyde for 30 min and washed with PBS. The BSC were incubated with

119 polyclonal anti-myogenic differentiation-1 (MYOD1; BS-2442R), anti-paired box-7 (Pax7)

120 (AB-528428) and anti-desmin Po (BS-20702R) at 1:100 dilutions for $1 \mathrm{~h}$ and then exposed to

121 (FITC)-conjugated goat anti-mouse or anti-rabbit IgG antibody (Santa Cruz Biotechnology, 
122 USA). Finally, The BSC subsequently were incubated in $0.1 \mu \mathrm{g} / \mathrm{mL}$

123 4',6-diamidino-2-phenylindole (DAPI) solution for $1 \mathrm{~min}$ and observed with a fluorescence

124 microscope (Olympus BX53F, Tokyo, Japan).

\section{Morphological analysis}

126 To assess the degree of myotube formation, the culture media was aspirated following $96 \mathrm{~h}$ of

127 differentiation, and the BSC were fixed with 10\% neutral buffered formalin (30 mM

$128 \mathrm{NaH}_{2} \mathrm{PO}_{4} \cdot \mathrm{H}_{2} \mathrm{O}, 54.6 \mathrm{mM} \mathrm{NaHPO} 4,40 \%$ formalin) for $30 \mathrm{~min}$ and stained with hematoxylin

129 solution (51275, Fluka Chemie GnbH, Switzerland) at room temperature for $5 \mathrm{~min}$. After $96 \mathrm{~h}$

130 differentiation, the BSC were fixed with $10 \%$ neutral buffered formalin for 10 min and stained

131 with an Oil Red O solution (O0625-25G, Sigma). After washing the BSC once with 60\%

132 isopropanol and twice with distilled water, the cells were photographed using a Nikon E5400

133 digital camera mounted on an optical microscope (Nikon TS100, Nikon Corporation, Japan).

134 Quantitative triacylglycerol assay

135 The concentration of triacylglycerol (TAG) was measured using a TAG quantification assay kit

136 (Applygen Inc., Beijing, China) according to the manufacturer's specifications. Cultured BSC

137 were washed with buffer to remove the residual medium and the cells lysed with a lysis buffer.

138 Accumulated TAG was digested with lipase for $3 \mathrm{~h}$ to release glycerol, and glycerol was

139 measured by spectrophotometric detection at $540 \mathrm{~nm}$. The glycerol assay is linear over a 
concentration range of 0 to $500 \mu \mathrm{M}$.

\section{$141 \quad$ Lipid droplet area quantification}

142 After $96 \mathrm{~h}$ of differentiation, lipid droplets of BSC were stained with Oil Red O. Images of 20

143 different regions of the slide were captured with a Nikon E5400 digital camera, followed by

144 computer image analysis using ImageJ software $1.43 \mathrm{u}$ (http://rsbweb.nih.gov/ij) as describe by

145 Deutsch et al. [7]. The analysis was performed by a threshold converting the 8-bit RGB image

146 into a binary image, which consists only of those pixels that represented the lipid droplets. The

147 acquired images were thresholded for the color saturation of the lipid droplet signal with the

148 threshold command option "pass". Following binarization, the image was subjected to

149 watershed object separation for image processing, which is used to identify borders of adjacent

150 lipid droplets. After separation, the binary image was manually compared with the original image

151 for consistency and to the control for correct binary conversion. Lipid droplets that were not

152 separated by water-shedding were corrected using the ImageJ pencil tool. After setting the scale

153 of the image, and the number and individual size of the lipid droplets in the image displayed by

154 ImageJ, surface area in $\mu^{2}$ was calculated. Incomplete droplets located at the edge of the image

155 were excluded. 
157 Following $96 \mathrm{~h}$ of BSC culture, total RNA of cultured BSC was isolated (duplicate six-well

158 culture plates for three independent experiments) with $500 \mu \mathrm{L}$ of TRI-Reagent (Sigma-Aldrich,

159 St. Louis, MO, USA). Genomic DNA was removed from extracted RNA with DNase (M610A,

160 Promega, Madison, WI) according to the manufacturer's instructions. The purity, concentration,

161 and integrity of the total RNA from each sample were quantified using a NanoDrop

162 spectrophotometer (Thermo Scientific, 2000C, Washington, DC) and the RNA 6000 Nano Assay

163 (Agilent Technologies, Palo Alto, CA) assessed the RNA integrity. The purity of the RNA

164 (A260/A280) was greater than 1.85, and the A260/A230 ratio was approximately 2.0 in all

165 samples. The concentration of RNA was determined from the absorbance at $260 \mathrm{~nm}$.

166 Complementary DNA (cDNA) was produced from $1 \mu \mathrm{g}$ of RNA using Taq-Man Reverse

167 Transcriptase Reagents (Applied Biosystems, Waltham, MA, USA) according to the protocol

168 recommended by the manufacturer. Random hexamers were used as primers for cDNA synthesis

169 (Table 1).

170 To characterize the degree of myogenesis, anti-paired box-3 (Pax3), Pax7, MYOD1, and

171 myogenin $(M Y O G)$ were selected as myogenic-specific marker genes. To characterize the degree

172 of adipogenic/lipogenic gene expression, $P P A R \gamma, C / E B P \alpha, C / E B P \beta$, and sterol regulatory

173 element-binding protein-1 (SREBP1) genes were selected. The genes stearoyl-CoA desaturase

$174(S C D)$, carnitine palmitoyltransferase $1(C P T 1)$, AMP-activated protein kinase alpha-1 $(A M P K \alpha)$,

175 lipoprotein lipase $(L P L), \mathrm{G}$ protein-coupled protein receptor-43 (GPR43), perilipin-2 (PLIN2), 
and fatty acid-binding protein 4 (FABP4) were selected. Each sample of the first-strand cDNA

177 was synthesized from 600 ng of total RNA using the QuantiTect Reverse Transcription Kit

178 (Qiagen, cat\#205313). Gene-specific primers (Table 1) were used to amplify target genes using

$17910 \mathrm{ng}$ of the first-strand cDNA as the template in a $15 \mu 1$ SYBR-green-based quantitative

180 RT-qPCR reaction performed under the following conditions: $95^{\circ} \mathrm{C}$ for 2 min, 45 cycles at $95^{\circ} \mathrm{C}$

181 for $10 \mathrm{sec}, 60{ }^{\circ} \mathrm{C}$ for $30 \mathrm{sec}, 72^{\circ} \mathrm{C}$ for $10 \mathrm{sec}$ with a melting curve from $65^{\circ} \mathrm{C}$ to $95^{\circ} \mathrm{C}$. Gene

182 expression levels were normalized to glyceraldehyde-3-phosphate dehydrogenase (GAPDH)

183 housekeeping gene expression in each sample. Transcript data were obtained in duplicate.

184 Relative expression was quantified by using the $2^{-\Delta \Delta C t}$ method. The cDNA from each sample was

185 pooled, serially diluted, quantified, and used for the creation of standard curves. Titration mRNA

186 primers for all genes against increasing amounts of cDNA yielded linear responses with slopes

187 between -2.8 and -3.0 . To reduce the contribution of assay-to-assay variation in the PCR assay

188 to the final results, all values were calculated relative to a calibration standard run in every

189 real-time PCR assay.

190 Adiponectin in BSC culture media

191 Adiponectin was measured in BSC culture media. Media samples were analyzed using a bovine

192 adiponectin ELISA kit (CSB-E14054B, CUSABIO, Houston, TX, USA) according to the

193 manufacturer's protocol. Adiponectin concentration was measured at $450 \mathrm{~nm}$ with a Biotek

194 Epoch Microplate Reader (Winooski, VT). The amount of adiponectin in the samples was 
calculated from a reference curve generated in the same assay with reference standards of known concentrations of adiponectin. Mean inter- and intra-assay precision for the adiponectin assay were $<8.4 \%$ and $<5.7 \%$, respectively.

\section{Construction of RNA-Seq library, quality control and sequencing}

After $96 \mathrm{~h}$ of BSC differentiation, total RNA was extracted from each treatments using TRIzol ${ }^{\mathrm{TM}}$ Reagent (Invitrogen, USA) according to the manufacturer's instructions. The isolated RNA was cleared of contaminating genomic DNA by DNase treatment (Thermo, USA). Prior to Illumina RNA sequencing, $1 \%$ nondenaturing agarose gel electrophoresis and a Nano-Photometer ${ }^{\circledR}$ spectrophotometer (IMPLEN, USA) were used to assess the quality and quantity of the isolated RNA, respectively. Samples satisfying the criteria of RNA integrity number (RIN) $>7$ were utilized for the following library preparation. RNA purification, reverse transcription, library construction and sequencing were completed by AMOGENE. Briefly, the mRNA was enriched by oligo(dT) beads, and was fragmented into short fragments through fragmentation buffer at $94{ }^{\circ} \mathrm{C}$ for 5 min. First strand cDNA was synthesized by a random hexamer primer (Illumina) and M-MuLV Reverse Transcriptase (Invitrogen, USA), using the short fragments as templates, at the condition of $25{ }^{\circ} \mathrm{C}$ for $10 \mathrm{~min}$, followed by $42{ }^{\circ} \mathrm{C}$ for $50 \mathrm{~min}$ for synthesis and $70{ }^{\circ} \mathrm{C}$ for $15 \mathrm{~min}$

for RTase inactivation. Second strand cDNA synthesis was subsequently performed using Second Strand Master Mix (Illumina) at $16{ }^{\circ} \mathrm{C}$ for $1 \mathrm{~h}$. Next, the cDNA fragments of $150 \sim 200 \mathrm{bp}$ in length were treated with T4 DNA polymerase and 5' phosphorylated, and then an adenine (A) 
214 residue was added to the $3^{\prime}$ ends of the DNA. Moreover, adapters were also ligated to the ends of

215 these target template DNAs. After ligation, the cDNA library was obtained by polymerase chain

216 reaction (PCR) amplification (5-9 cycles). Finally, PCR products were purified, and library

217 quality was evaluated on an Agilent. Bioanalyzer 2100 system (Agilent Technologies, USA). The

218 library preparations were sequenced on an Illumina Hiseq 4000 platform using paired-end

219 technology following the manufacturer's standard guidelines.

220 Fastp was used to filter the original sequencing data to obtain clean data, and the filtered data

221 were evaluated with RSeQC software package to obtain high-quality sequencing data, and then

222 STAR（Spliced Transcripts Alignments to a Reference, STAR） software was used for sequence

223 alignment analysis with the reference genome.

224 Differentially expressed genes (DEGs) identification

225 Cuffdiff was used to assemble the RNA-Seq alignments and estimate gene expression and

226 transcript. The edgeR package was used for the identification of DEGs within samples. Genes

227 with statistical significance were retained first (q-value $<0.05)$; significant DEGs were compared

228 with a fold change of $>1.5$ than 1.5 or $<0.667$ were retained $[\log 2(1.5)=0.5849 ; \log 2(0.667)=$

$229-0.5849]$.

\section{Functional enrichment analysis}


231 The DEGs were subjected to Kyoto Encyclopedia of Genes and Genomes (KEGG) pathway and

232 enrichment analysis of Gene Ontology (GO). KEGG enrichment analysis was to identify the

233 pathways of significant enrichment of DEGs, gene function, genomic information, and functional

234 information. The GO classification includes the following three aspects: biological process $(B P)$,

235 molecular function $(M F)$, and cellular component $(C C)$, which define and describe the functions

236 of selected genes and corresponding proteins. KEGG was separately generated by

237 (www.genome.jp/kegg).

\section{Statistical analysis}

239 All data are presented as mean \pm SEM. One-way ANOVA analysis of variance with a post hoc

240 Turkey's multiple comparison test was used to evaluate the statistical significance of differences

241 among the treatments. Graph Pad Prism 6.0. Statistical significance was set at $P<0.05$.

242 Results

243 Identification of skeletal muscle satellite cells

244 MYOD1 antibodies were used to monitor the myogenic differentiation of BSC and desmin and

245 Pax7 antibodies to characterize proliferation-positive BSC by immunofluorescence staining

246 (Figure 1).

\section{Average BSC size and cell viability}

248 A total of $1,125 \pm 7.82$ cells for each treatment were analyzed for the measurement of average 
249 cell size. There was no difference in BSC size and cell viability among treatments $(P=0.57)$

250 (Figure 2).

\section{BSC differentiation and lipid accumulation}

252 Control BSC proliferated and subsequently fused to form myotubes. Upon incubation of BSC

253 with ciglitazone, the cells became adipocyte-like cells, an effect that was clearly evident after 96

$254 \mathrm{~h}$ (Figure 3). Increasing the concentration of ciglitazone greatly accelerated the appearance of

255 adipocyte-like cells, and strongly increased the number of BSC that differentiated into adipocytes.

256 Exposure of post-confluent cells to the differentiation medium plus ciglitazone decreased

257 myotube formation, with a concomitant increase in the area of cells containing lipid droplets and

258 the formation of adipoblasts.

259 Concentration of triacylglycerol and lipid droplet area

260 The concentration of cellular TAG, the main component of lipid droplets, was elevated linearly

261 by $\mathrm{CL}, \mathrm{CM}$, and $\mathrm{CH}$ treatments and, correspondingly, CL, CM, and $\mathrm{CH}$ treatments caused a

262 profound increase in the percent area of lipid droplets (Figure 4) $(\mathrm{P}<0.01)$.

\section{Myogenic gene expression}

264 The CL, CM, and CH treatments increased Pax3 and Pax7 expression and decreased MYOD,

265 MYOG, MYF4, and MRF5 expression relative to $\mathrm{CON}(P<0.01)$ (Figure 5). The expression of

266 MYF4 and MRF5 were least in the CH-treated BSC $(P<0.01)$. 
268 There was a dose-response to ciglitazone addition for the expression of adipogenic transcription

269 factors $P P A R \gamma, C / E B P \alpha, C / E B P \beta, S R E B P 1, A C C$, and $F A S(P<0.01)$, and the greatest increase

270 in the expression of these genes, were caused by CH-treated BSC (Figure 6)

271 Relative expression of SCD, LPL, GPR43, FABP4, and PLIN2 was dose-dependent as the

272 addition level of ciglitazone increased $(P<0.01)$ (Figure 7). Expression of $C P T 1$ was depressed

273 by the CL, CM, and CH-treated BSC stepwise relative to CON BSC. Expression of $A M P K \alpha(P<$

274 0.01) was greater in CL, CM, and $\mathrm{CH}$-treated BSC than in CON BSC, and the CM treatment

275 caused the greatest increase.

\section{Culture media adiponectin}

277 Compared with $\mathrm{CON}$ BSC, the $\mathrm{CL}, \mathrm{CM}_{2}$ and $\mathrm{CH}$ treatments increased the amount of adiponectin $278(A D P)$ secretion $(P<0.01)$, and the highest concentration of $A D P$ was caused by the $\mathrm{CH}$

279 treatment (Figure 8).

\section{Analysis of differentially expressed genes in BSC}

281 Whole-genome expression profiling with RNA-Sequencing analysis revealed significant

282 differentially expressed genes $(D E G s)$ when the BSC were treated with different level of

283 ciglitazone. Compared with CON, the CL treatment up-regulated 611 genes and down-regulated

284510 genes; the CM treatment up-regulated 565 genes and down-regulated 527 genes; whereas the 
$285 \mathrm{CH}$ treatment up-regulated 501 genes and down-regulated 435 genes (Table 2). Combined with 286 the analysis of these results of differential expressed genes, BSC treated with CL, CM and CH 287 had $281 D E G s$ as shown in the volcano map (Figure 9A, B, and C).

\section{Gene ontology (GO) analysis of DEGs in BSC}

289 Pathway analysis of $D E G s$ was performed to understand the biological relationship between 290 pathways and molecules. The Gene Ontology (GO) annotation was classified into three clusters:

291 biological process (BP), molecular function (MF), and cellular component (CC). The 10 top 292 significantly enriched GO terms in which the calculated by the hypergeometric test was Q $<0.05$

293 were selected. As shown in Figure 10 (Supplementary S1), biological pathways were 294 significantly changed by GO terms of ciglitazone-treated BSC. Top 10 GO enrichment analysis 295 significantly changed cell proliferation, protein trimerization, fat cell differentiation, cellular 296 response to external stimulus, positive regulation of release of cytochrome $\mathrm{c}$ from mitochondria, 297 and type B pancreatic cell proliferation process. Molecular functions such as nuclease activity, 298 endonuclease activity, deoxyribonuclease activity, growth factor activity, kinase inhibitor activity, 299 biotinidase activity, and receptor-ligand activity were up-regulated by ciglitazone.

300 KEGG enrichment of DEGs in BSC

301 Pathway analysis of $D E G s$ was conducted to understand the pathways and molecular interactions 302 involved with ciglitazone treatment. The 10 top significantly enriched GO terms in which the 
calculated by the hypergeometric test was $Q<0.05$ were selected. Enrichment degree was

304 identified by Gene Ratio, P. adjust, and enriched genes. In the CL treated BSC, KEGG enrichment analysis indicated that a total of 465 DGEs were enriched in 31 pathways and mainly

306 in glycine, serine, and threonine metabolism, TNF signaling pathway, and the p53 signaling

307 pathway. Genes with up-regulated expression were mainly enriched in mineral absorption,

308 transcriptional misregulation in cancer, choline metabolism in cancer, glutathione metabolism.

309 Genes with down-regulated expression were mainly enriched in the TNF signaling pathway,

310 biosynthesis of amino acids, protein digestion, and absorption.

311 In the CM treated BSC, a total of 484 DGEs were enriched in 18 pathways and mainly in

312 apoptosis, p53 signaling pathway, non-alcoholic fatty liver disease (NAFLD), PI3K-Akt

313 signaling pathway, wnt signaling pathway, and TNF signaling pathway. Genes with up-regulated

314 expression were mainly enriched in TNF signaling pathway, the calcium signaling pathway,

315 apoptosis, RNA degradation, and genes with down-regulated expression were mainly enriched in

316 the biosynthesis of amino acids, p53 signaling pathway, ribosome, carbon metabolism, and the

317 PI3K-Akt signaling pathway. In the $\mathrm{CH}$ treated BSC, a total of 397 DGEs were enriched in 30

318 pathways and mainly in the p53 signaling pathway, PPAR signaling pathway, biosynthesis of

319 amino acids, pentose phosphate pathway, and TGF-beta signaling pathway. Genes with

320 up-regulated expression were mainly enriched in the calcium signaling pathway, PPAR signaling

321 pathway, purine metabolism, nicotinate and nicotinamide metabolism, and genes with 
322 down-regulated expression were mainly enriched in the biosynthesis of amino acids p53

323 signaling pathway, glycine, serine, and threonine metabolism, pyrimidine metabolism, and

324 carbon metabolism (Figure 11, Supplementary S2).

\section{KEGG Pathway Enrichment Analysis of DEGs}

326 Effects of increasing concentrations of ciglitazone on the pathway of PPAR $\gamma$ enrichment

327 As ciglitazone is a PPAR $\gamma$ agonist, we analyzed the PPAR-signaling pathway enriched by DEGs

328 during adipogenic trans-differentiation of BSC induced by different concentrations of ciglitazone

329 (Figure 12). The high-concentration of ciglitazone significantly up-regulated the PPAR signaling

330 pathway, there were 10 genes differentially enriched in this pathway, and the proportion of

331 differentially enriched genes was 10/397. Pathway analysis of differentially enriched genes

332 indicated 7 up-regulated genes and 3 down-regulated genes. Based on the up-regulated

333 expression of $P P A R \gamma$, the downstream fatty acid transport-related genes $(D B I, F A B P 3)$, fatty acid

334 oxidation-related genes ( $C P T-2, S C P 2, F A B P 3)$, adipocyte differentiation-related genes

335 (ANGPTL4, glycogen neogenesis gene $G K$ ), and the adipocyte differentiation-related gene

$336 F A B P 7$ were up-regulated. The expression of $M M P-1$ and the ketogenic gene $H M G C S 2$ was

337 down-regulated (Figure 13).

\section{Discussion}

339 This study addressed the hypothesis that ciglitazone as a PPAR $\gamma$ ligand in the absence of an 
340 adipocyte differentiation cocktail would increase adiponectin and adipogenic gene expression in

341 BSC. Previous studies investigated TZD as an extrinsic factor that influences myogenic satellite

342 cells by inducing the expression of several transcription factors, including $P P A R \gamma$ and $C / E B P \alpha[8$,

343 9]. In cases where the conditions of the adipocytes containing the $P P A R \gamma$ activator permit, these

344 cells can differentiate into mature adipocytes [10]. Li et al. [11] assumed that myoblasts and

345 adipocytes have similar bio-initiating sources, and the potential for trans-differentiation to

346 produce marbling or intramuscular lipogenesis was hypothesized. specific genes during differentiation [13]. In the present study, the decrease in the myotube

351 formation and the increase in the accumulation of lipid droplets caused by ciglitazone addition in

352 BSC. This may indicate that ciglitazone could induce the BSC to differentiate into adipocytes. adipocytes by ectopic expression of adipose trans-differentiation factors such as PPAR [15].

356 Previous studies had documented that when the PPAR $\gamma$ gene was overexpressed in G8 myoblasts 357 under optimal culture conditions for muscle differentiation, the expression levels of myogenic 358 factors $M R F 5, M Y O D$, and MYF4 were depressed, and the myoblasts could not differentiate into 
359 myotubes [16]. In mammalian cells, $P P A R \gamma$ and $C / E B P \alpha$ are major regulators of lipogenesis and

360 be transcription targets [17]. PPAR $\gamma$ is induced during the differentiation of preadipocytes into

361 adipocytes, which is critical for precursor cells to differentiate into mature adipocytes [18].

362 Adipocyte differentiation also involves the expression of several other transcription factors that

363 interact at different the process of adipogenesis to produce mature adipocytes [19].

364 Lydia et al. demonstrated that TZDs specifically bind to and activate PPAR , increase the 365 expression of PPAR $y$ and related adipokines, and promote adipocyte differentiation [20].

366 Kageyama et al. [21] demonstrated that pioglitazone increased body weight by selectively

367 stimulating PPAR $\gamma$ and promoting lipid storage in white adipose tissue. Lizcano et al. [22]

368 reported that JMJD2C could inhibit $P P A R \gamma$ activity and reduce triglyceride accumulation in

369 adipocytes. Although $P P A R \gamma$ and $C / E B P \alpha$ are highly synergistic in the adipogenic process,

370 adipocyte genes vary in their reliance on $C / E B P \alpha$ and $P P A R \gamma$ [23].

$371 \quad \operatorname{Pax} 3$ and $\operatorname{Pax} 7$ are markers of the differentiation of mesenchymal cells toward a myogenic

372 cell lineage. Up-regulation of the expression of $\operatorname{Pax} 3$ and $\operatorname{Pax} 7$ increases the expression of

373 myogenic regulatory factors [24], which include $M Y O D$ and MYOG. Up-regulation of MYOD

374 expression promotes the conversion of somite-derived cells into myoblasts; $M Y O G$ is involved in

375 the fusion of myoblasts to form myotubes [25]. Cornelison et al. [26] identified MYOD was a key

376 negative regulator of brown adipocyte development. Similarly, Wang et al. [27] reported that

377 MYOD negatively regulated the f brown adipocyte development and concluded that loss of 
378 MYOD facilitates adipogenic trans-differentiation of myoblasts in vivo. The PLIN2 is primarily

379 expressed during the early stages of adipocyte differentiation, which promotes lipid droplet

380 accumulation in muscle cells [28]. Studies with 3T3-L1 adipocytes indicated that PLIN2 could

381 be used as a marker gene for precursors during adipocyte differentiation [29]. In this study,

382 ciglitazone in the absence of an adipocyte differentiation cocktail also induced an up-regulation

383 of adipogenic gene expression accompanied by low expression of MYOD. And the higher PLIN2

384 expression and adiponectin promotes the higher lipid droplets accumulation in the BSC [4].

Whole-genome RNA-Seq GO analysis and KEGG enrichment analysis of DEGs showed

386 that most $D E G s$ were closely related to cell proliferation, cell differentiation and cell metabolic

387 processes. PPAR signaling pathway, P53 signaling pathway, Wnt signaling pathway, ribosome,

388 signaling pathway regulating pluripotency of stem cells, TNF signaling pathway, and calcium

389 signaling pathway participate in the adipogenic trans-differentiation process of BSC. The hign

390 concentration of ciglitazone significantly up-regulated the PPAR signaling pathway, and 7 out of

39110 genes were up-regulated in this pathway. Besides, the increase in accumulation of lipid

392 droplets and the concentration of $T A G$ and adiponectin further indicated the regulatory role of

393 PPAR $\gamma$ in adipogenic trans-differentiation of BSC.

The PI3K-Akt signaling pathway plays an important regulatory role in adipocyte 

tissue contains adult stem cells (ADSCs) similar to mesenchymal stem cells, which inhibit

399 adipogenic differentiation by activating the Wnt signaling pathway [34-36]. In this study, the

400 RNA sequencing results revealed that the low-concentration of ciglitazone could down-regulated

401 the genes in the regulation of the Wnt signaling pathway, which revolved in the adipogenesis and 402 lipid metabolism.

TGF- $\beta 1$ is a factor activated by inflammation and participates in the process of chronic

404 fibrosis of organs. TGF- $\beta 1$ transmits fibrotic signals through its downstream kinase substrate

405 Smads protein. The TGF- $\beta 1 /$ Smad3 signaling pathway and organ fibrosis are closely related.

406 TGF- $\beta 1$ binds to its receptor on the cell membrane causes intracellular Smad 2 and Smad3

407 phosphorylation and Smad4 binds to form a complex that enters the nucleus and cooperates with

408 other transcription factors to regulate the expression of genes related to cell proliferation and

409 differentiation [37-40]. In our study, the high concentration of ciglitazone can inhibit the

410 activation of TGF- $\beta 1 / \mathrm{Smad} 3$ signaling pathway. his may suggest that ciglitazone could promote

411 the adipocyte phenotype in BSC through these signaling pathways.

\section{Conclusions}

413 These results indicate that ciglitazone as a PPAR $\gamma$ agonist can promote lipid droplet

414 formation and triglyceride accumulation in BSC, and effectively increase adiponectin

415 concentration and adipogenic gene expression. RNS-seq showed that treatment with different 
416 concentrations of ciglitazone significantly affected the p53 signaling pathway, PPAR signaling

417 pathway, TNF signaling pathway, PI3K-Akt signaling pathway and Wnt signaling pathway. In

418 conclusion, our results support at least partial conversion of BSC to adipocytes by ciglitazone in

419 the presence of an adipocyte differentiation cocktail. Further experiments are needed to elucidate

420 the molecular mechanisms by which PPAR $\gamma$ affects lipogenesis during the process of adipogenic

421 differentiation of BSC and the regulatory pathways that influence other regulators of lipid

422 production.

\section{DECLARATIONS}

424 Abbreviations

425 ACC: Acetyl CoA carboxylase; ADP: adiponectin; AMPK $\alpha$ : Adenosine 5 '-monophosphate

426 (AMP)-activated protein kinase; BSC: bovine satellite cells; C/EBP $\alpha$ : CAAT/enhancer-binding

427 protein alpha; C/EBPß: CCAAT/enhancer-binding protein beta; CPT1: carnitine

428 palmitoyltransferase; DMEM: Dulbecco's modified Eagle medium; FABP4: fatty acid binding

429 protein4; FAS: Fatty acid synthetase; FBS: fetal bovine serum; GAPDH:

430 glyceraldehyde-3-phosphate dehydrogenase; GPR43: G protein-coupled protein receptor 43;

431 KEGG: Kyoto Encyclopedia of Genes and Genomes; LPL: lipoprotein lipase; MRF5:

432 Myogenic Regulatory Factor5; MYF4: Myogenin4; MYOG: myogenin; MYOD: myogenic

433 differentiation; Pax3: Paired box 3; Pax7: Paired box 7; PLIN2: perilipin 2; PPAR $\gamma$ :

434 peroxisome proliferator-activated receptor gamma; RT-qPCR: Real-time quantitative reverse 
transcription PCR; RNA-Seq: RNA sequencing; SCD: stearoyl-CoA desaturase; SREBP1:

436 sterol regulatory element-binding protein 1; TAG: triacylglycerol; TZD: thiazolidinedione

437 Acknowledgements

438 The authors would like to thank the members of their laboratory for helpful and constructive 439 advice. The authors would like to thank Editage (www.editage.co.kr) for English language 440 editing and the academic editor and reviewers for their useful comments, which helped to 441 improve this manuscript greatly.

\section{Authors' contributions}

443 The authors contribution are as follows: X. Z. Li, S.H. Choi and S. B. Smith concieved and

444 designed the experiments. S. B. Smith was the principal investigator and contributed to 445 interpretation of the findings and editing for English usage. J. F Zhang, Y. Yan, J. F. Sun, Y.

446 Wang, Y. Cui and S. Naseem, performed all the laboratory works. J. F Zhang, Y. Yan and J. F. Sun 447 were the major contributors in writing the manuscript along with X. Z. Li. B. Sun, A. Manzoor 448 and J. Yu contributed to subject briefings and data collection and analyses, Critical revision was 449 performed by X. Z. Li, S.H. Choi and S. B. Smith. All authors read and approved the final 450 manuscript.

\section{Ethics approval and consent to participate}


452 All experimental procedures were approved by the Yanbian University Institutional Animal Care

453 and Use Committee.

\section{Consent for publication}

455 Not applicable.

\section{Avaialabilty of data and materials}

457 The datasets generated and/or analysed during the conduct of the study are included in this 458 published article. Upon reasonable request, the datasets of this study are available from the 459 corresponding author.

\section{Competing interests}

461 The authors declare that they have no competing interests.

\section{$462 \quad$ Funding}

463 This study was made possible through a gran (Code 31660667) from the National Natural 464 Science Foundation in China and a grant (code NRF-2018R1D1A3B07048219) from the 465 National Research Foundation in Korea.

\section{$467 \quad$ References}

468 1. Poulos SP, Hausman GJ. A comparison of thiazolidinedione-induced adipogenesis and 
myogenesis in stromal-vascular cells from subcutaneous adipose tissue or semitendinosus muscle of postnatal pigs. J Anim Sci. 2006; 84(5):1076-82.

471

472

473

474

475

476

477

478

479

480

481

482
2. Yeow K, Phillips B, Dani C, Cabane C, Amri EZ, Dérijard B.Inhibition of myogenesis enables adipogenic transdifferentiation in the C2C12 myogenic cell line. FEBS Lett. 2001; 506(2):157-62.

3. Singh NK, Chae HS, Wang IH, Yoo YM, Chung HY. Transdifferentiation of porcine satellite cell to adipoblasts with ciglitizone. J Anim. Sci. 2007; 85(5):1126-35.

4. Li XZ, Yan Y, Zhang JF, Sun JF, Sun B, Yan CG, et al. Oleic acid in the absence of a PPAR $\gamma$ agonist increases adipogenic gene expression in bovine muscle satellite cells. J Anim Sci. 2019; 97(10):4114-23.

5. Teboul LD, Gailliard L, Staccini H, Inadera EZ, Amri P, Grimaldi A. Thiazolidinediones and fatty acids convert myogenic cells into adipose-like cells.J Biol Chem.1995;47:28183-28187.

6. Chung KY, Lunt DK, Choi CB, Chae SH, Rhoades RD, Adams TH, et al. Lipid characteristics of subcutaneous adipose tissue and M. longissimus thoracis of Angus and Wagyu steers fed to US and Japanese endpoints. Meat Sci. 2006;73(3):432-41.

7. Deutsch MJ, Schriever SC, Roscher AA, Ensenauer R. Digital image analysis approach for lipid droplet size quantitation of Oil Red O-stained cultured cells. Anal Biochem. 2014;445:87-9. 
8. Choi S H, Park, SK, Johnson BJ, Chung KY, Choi CW, Kim K H, et al. AMPK $\alpha$, C/EBP $\beta$, CPT1 $\beta$, GPR43, PPAR $\gamma$, and SCD gene expression in single- and co-cultured bovine satellite cells and intramuscular preadipocytes treated with palmitic, stearic, oleic, and linoleic acid. J Anim Sci. 2015;28(3):411-9.

9. Hu E, Tontonoz P, Spiegelman BM. Trandifferentiation of myoblasts by the adipogenic transcription factor PPAR- $\gamma$ and C/EBP- $\alpha$. Proc Natl Acad Sci. 1995;92(21): 9856-60.

10. Fujiki K, Kano F, Shiota K, Murata M. Expression of the peroxisome proliferator activated receptor gamma gene is repressed by DNA methylation in visceral adipose tissue of mouse models of diabetes. BMC Biology. 2009;7(1):38.

11. Li WC, Yu WY, Quinlan JM, Burke ZD, Tosh D. The molecular basis of transdifferentiation. J Cel Mol Med. 2007;9(3):569-82.

13. Hassumi MY, Silva-Filho VJ, Campos-Júnior JC, Vieira SM, Cunha FQ, Alves P M, et al. PPAR-gamma agonist rosiglitazone prevents inflammatory periodontal bone loss by inhibiting osteoclastogenesis. Int Immunopharmacol. 2009;9(10):1150-8. 
BMP-2 enables differential differentiation of $\mathrm{C}_{2} \mathrm{C}_{12}$ cells into adipocytes and osteoblasts.

$506 \quad$ Nucleic Acids Res. 2004;32(1):e1.

507 15. Yablonka-Reuveni Z, Day K, Vine A, Shefer G. Defining the transcriptional signature of $508 \quad$ skeletal muscle stem cells. J Anim Sci. 2008;86(140):E207-16.

509

510

511

512

513

514

515

516

517

518

519

16. Rehfeldt C, Kuhn G. Consequences of birth weight for postnatal growth performance and carcass quality in pigs as related to myogenesis. J Anim Sci. 2006 Apr;84 Suppl:E113-23.

17. Moseti D, Regassa A, Kim WK. Molecular regulation of adipogenesis and potential anti-adipogenic bioactive molecules. Int J Mol Sci, 2016;17(1):124.

18. Lefterova MI, Lazar MA. New developments in adipogenesis. Trends Endocrin Met. $2009 ; 20(3): 107-114$.

19. Kim JB, Wright HM, Wright M, Spiegelman BM. ADD1/SREBP1 activates PPAR $\gamma$ through the production of endogenous ligand. Proc Natl Acad Sci. 1998;95:4333-7.

20. Lydia T, Danielle G, Laurence S, Hidekuni I, Ez-Zoubir A, Paul AG. Thiazolidinediones and fatty acids convert myogenic cells into adipose-like cells. J Bio Chem. 1995;270:28183-28187.

21. Kageyama H, Hirano T, Okada K, Ebara T, Adachi M. Lipoprotein lipase mRNA in white adipose tissue but not in skeletal muscle is increased by pioglitazone through PPAR $\gamma$. Biochem Biophys Res Commun. 2003;305(1): 22-7. 
523 22. Lizcano F, Romero C, Vargas D. Regulation of adipogenesis by nuclear receptor PPAR $\gamma$ is 524 modulated by the histone demethylase JMJD2C. Genet Mol Biol. 2011;34(1):19-24.

525 23. Haakonsson AK, Stahl MM, Nielsen RA, Mandrup S. Acute genome-wide effects of 526 rosiglitazone on PPARgamma transcriptional networks in adipocytes. Mol

$527 \quad$ Endocrinol. 2013;27(9):1536-49.

528 24. Cossu G. Wnt signaling and the activation of myogenesis in mammals. EMBO J. $529 \quad$ 1999;18(24):6867-72.

25. Stewart CE, Rittweger J. Adaptive processes in skeletal muscle: molecular regulators and genetic influences.J Musculoskelet Neuronal Interact. 2006;(6):73-86.

26. Cornelison DW, Bradley BO, Michael AR, Barbara JW. MYOD(-/-) satellite cells in single-fiber culture are differentiation defective and MRF4 deficient. Dev Biol. transdifferentiation of myoblasts into brown adipocytes. EBio Med. 2017;16:212-3. $2000 ; 224(2): 122-37$ al. Adipocyte differentiation-related protein and OXPAT in rat and human skeletal muscle: involvement in lipid accumulation and type 2 diabetes mellitus. J Clin Endocrinol Metab. 2009;94(10):4077-85. 
29 Dodson SW, Duarte M, Du M, Bergen WG. Cell supermarket: Adipose tissue as a source of stem cells. J Genom. 2013;1:39-44.

31. Kliewer SA, Forman BM, Blumberg B, Kliewer Forman SA, Blumberg B, Ong ES, et al. Differential expression and activation of a family of murine peroxisome proliferator-activated receptors. Proc Natl Acad Sci. 1994;91(15):7355-9.

32. Yi X, Liu J, Wu P, Gong Y, Xu X, Li W. The whole transcriptional profiling of cellular metabolism during adipogenesis from hMSCs. J Cell Physiol. 2020 Jan;235(1):349-363.

33. Barthel A, Okino ST, Liao J, Nakatani K, Li J, Whitlock JP Jr, Roth RA. Regulation of GLUT1 gene transcription by the serine/threonine kinase Akt1. J Biol Chem. 1999 Jul $16 ; 274(29): 20281-6$.

34. Ross SE, Hemati N, Longo KA, Bennett CN, Lucas PC, Erickson RL, MacDougald OA. Inhibition of adipogenesis by Wnt signaling. Science. 2000 Aug 11;289(5481):950-3.

35.Prestwich TC, Macdougald OA. Wnt/beta-catenin signaling in adipogenesis and metabolism. Curr Opin Cell Biol. 2007 Dec;19(6):612-7.

36.Kang S, Bajnok L, Longo KA, Petersen RK, Hansen JB, Kristiansen K, MacDougald OA. Effects of Wnt signaling on brown adipocyte differentiation and metabolism mediated by PGC-1alpha. Mol Cell Biol. 2005 Feb;25(4):1272-82.

37. Budi EH, Duan D, Derynck R. Transforming Growth Factor- $\beta$ Receptors and Smads: 
561 38.Kang JS, Liu C, Derynck R. New regulatory mechanisms of TGF-beta receptor function.

562 Trends Cell Biol. 2009 Aug;19(8):385-94.

563 39.Fabregat A, Jupe S, Matthews L, Sidiropoulos K, Gillespie M, Garapati P, et al. The

564 Reactome Pathway Knowledgebase. Nucleic Acids Res. 2018 Jan 4;46(D1):D649-D655.

565 40.Yue Y, Meng K, Pu Y, Zhang X. Transforming growth factor beta (TGF- $\beta$ ) mediates cardiac

566 fibrosis and induces diabetic cardiomyopathy. Diabetes Res Clin Pract. 2017

567 Nov;133:124-130.

\section{Figure legends}

Figure 1. Immunofluorescence staining showed that the nucleus after DAPI staining was blue, and Pax7 (a), MYOD1 (b) and Desmin (c) were green in the cytoplasm. The original magnification was $40 \times($ scale bars $=200 \mu \mathrm{m})$. Results represent three independent experiments.

Figure 2. Effects of ciglitazone on average cell size and cell viability in BSC after $96 \mathrm{~h}$ in 
culture. CON, DMEM $+2 \%$ horse serum (I); CL, CON $+5 \mu \mathrm{M}$ ciglitazone; CM, $\mathrm{CON}+10 \mu \mathrm{M}$ ciglitazone; $\mathrm{CH}, \mathrm{CON}+20 \mu \mathrm{M}$ ciglitazone. Values are means of 6 culture dishes derived from six animals. ${ }^{a, b, c}$ Means within a panel with common superscripts are not different $(P>0.05)$.

Figure 3. Oil Red O- and hematoxylin-stained bovine satellite cells (BSC) cultured with ciglitazone in Dulbecco's modified Eagle`s medium (I) containing 2\% horse serum after $96 \mathrm{~h}$ culture. A, CON (DMEM $+2 \%$ horse serum); B, CL $(\mathrm{CON}+5 \mu \mathrm{M}$ ciglitazone); $\mathrm{C}, \mathrm{CM}(\mathrm{CON}+10 \mu \mathrm{M}$ ciglitazone); $\mathrm{D}, \mathrm{CH}(\mathrm{CON}+20 \mu \mathrm{M}$ ciglitazone). Scale bars $=200 \mu \mathrm{m}$.

Figure 4. Effect of ciglitazone on triacylglycerol and percent lipid droplet area in BSC after $96 \mathrm{~h}$ of culture. CON, DMEM $+2 \%$ horse serum; CL, CON $+5 \mu \mathrm{M}$ ciglitazone; $\mathrm{CM}, \mathrm{CON}+10 \mu \mathrm{M}$ ciglitazone; $\mathrm{CH}, \mathrm{CON}+20 \mu \mathrm{M}$ ciglitazone. Error bars are mean \pm S.E. The letters $a, b, c$, and $d$ indicate a significant difference $(\mathrm{P}<0.01)$ within an item compared with undifferentiated cells. The results are representative of six independent experiments.

Figure 5. Myogenic gene expression: Pax3, Pax7, MYOD, MYOG, MYF4 and MRF5 gene expression in BSC cultured with ciglitazone in Dulbecco's modified Eagle medium containing $2 \%$ horse serum after $96 \mathrm{~h}$ of incubation. CON, DMEM $+2 \%$ horse serum; $\mathrm{CL}, \mathrm{CON}+5 \mu \mathrm{M}$ ciglitazone; $\mathrm{CM}, \mathrm{CON}+10 \mu \mathrm{M}$ ciglitazone; $\mathrm{CH}, \mathrm{CON}+$ 
$20 \mu \mathrm{M}$ ciglitazone. The results of gene expression were consistent with protein expression. The bars are the means $\pm \mathrm{SE}$. The letters $a, b, c$, and $d$ indicate a significant difference $(\mathrm{P}<0.01)$ within an item compared with undifferentiated cells. The results are representative of six independent experiments.

Figure 6. Adipogenic gene expression: PPAR $\gamma, \mathrm{C} / \mathrm{EBP} \beta, \mathrm{SREBP} 1, \mathrm{C} / \mathrm{EBP} \alpha, \mathrm{ACC}, \mathrm{FAS}$ gene expression in BSC cultured with ciglitazone in Dulbecco's modified Eagle medium containing $2 \%$ horse serum after $96 \mathrm{~h}$ of incubation. CON, DMEM $+2 \%$ horse serum; $\mathrm{CL}, \mathrm{CON}+5 \mu \mathrm{M}$ ciglitazone; $\mathrm{CM}, \mathrm{CON}+10 \mu \mathrm{M}$ ciglitazone; $\mathrm{CH}, \mathrm{CON}+$ $20 \mu \mathrm{M}$ ciglitazone. The results of gene expression were consistent with protein expression. Error bars are the means $\pm \mathrm{SE}$. The letters $a, b, c$, and $d$ indicate a significant difference $(\mathrm{P}<0.01)$ within an item compared with undifferentiated cells. The results are representative of six separate experiments.

Figure 7. Gene Expression Associated with lipid metabolism: $C P T 1, S C D, A M P K \alpha, L P L$, GPR43, FABP4, PLIN2 gene expression in BSC cultured with ciglitazone in Dulbecco's modified Eagle medium (I) containing 2\% horse serum at $96 \mathrm{~h}$ incubation time. $\mathrm{CON}, \mathrm{DMEM}+2 \%$ horse serum; $\mathrm{CL}, \mathrm{CON}+5 \mu \mathrm{M}$ ciglitazone; $\mathrm{CM}, \mathrm{CON}+10 \mu \mathrm{M}$ ciglitazone; $\mathrm{CH}, \mathrm{CON}+20 \mu \mathrm{M}$ ciglitazone. The results of gene expression were consistent with protein expression. The bars are the means $\pm \mathrm{SE}$. The letters $a, b, c$, and $d$ indicate a significant difference $(\mathrm{P}<0.01)$ within an item 
compared with undifferentiated cells. The results are representative of six independent experiments.

Figure 8. Adiponectin concentration $(\mu \mathrm{g} / \mathrm{mL})$ in media from BSC cultured for $96 \mathrm{~h}$ with ciglitazone in Dulbecco's modified Eagles medium containing 2\% horse serum at $96 \mathrm{~h}$ incubation time. CON, DMEM $+2 \%$ horse serum; CL, CON $+5 \mu \mathrm{M}$ ciglitazone; $\mathrm{CM}, \mathrm{CON}+10 \mu \mathrm{M}$ ciglitazone; $\mathrm{CH}, \mathrm{CON}+20 \mu \mathrm{M}$ ciglitazone. The bars are the mean $\mathrm{s} \pm \mathrm{SE}$. The letters $a, b, c$, and $d$ indicate a significant difference (P $<0.01)$ within an item compared with undifferentiated cells. The results are representative of six independent experiments.

Figure 9. Differentially Expressed Genes (A) Heatmap for the Figure hierarchical cluster analysis of differentially expressed genes (DEGs) after differentiation of BSC in Yanbian Yellow Cattle with different concentrations of ciglitazone.(B) Wayne map and (C) Volcano Plot. Red represents up regulated genes and blue represents down-regulated genes. CON, DMEM $+2 \%$ horse serum; $\mathrm{CL}, \mathrm{CON}+5 \mu \mathrm{M}$ ciglitazone; $\mathrm{CM}, \mathrm{CON}+10 \mu \mathrm{M}$ ciglitazone; $\mathrm{CH}, \mathrm{CON}+20 \mu \mathrm{M}$ ciglitazone .

Figure 10. Gene Ontology (GO) classification of differentially expressed genes (DEGs) after differentiation of BSC in Yanbian Yellow Cattle with different concentrations of ciglitazone. CON, DMEM $+2 \%$ horse serum; $\mathrm{CL}, \mathrm{CON}+5 \mu \mathrm{M}$ ciglitazone; $\mathrm{CM}$, $\mathrm{CON}+10 \mu \mathrm{M}$ ciglitazone; $\mathrm{CH}, \mathrm{CON}+20 \mu \mathrm{M}$ ciglitazone. 
633 Figure 11. KEGG functional enrichment of transcriptome from skeletal muscle satellite cells

634

635

636

637

638

639

640

641 of different doses of ciglitazone. CON, DMEM $+2 \% \mathrm{HS}$; CON-CL, CON $+5 \mu \mathrm{M}$

ciglitazone; CON-CM: $\mathrm{CON}+10 \mu \mathrm{M}$ ciglitazone; $\mathrm{CON}-\mathrm{CH}, \mathrm{CON}+20 \mu \mathrm{M}$

ciglitazone.

Figure 12. PPAR signaling pathway regulated by high the concentration of ciglitazone.

Figure 13. Distribution of up- and down-regulated genes enrichment in different Kyoto

Encyclopedia of Genes and Genomes (KEGG) pathways. Pathway nodes (yellow), up-regulated genes (red), and down-regulated genes (green) are represented by circles. 
Table 1. Forward and reverse primers for Real-time PCR

\begin{tabular}{|c|c|c|c|}
\hline \multirow{2}{*}{$\begin{array}{l}\text { Genes } \\
\text { Pax3 }\end{array}$} & \multirow{2}{*}{$\begin{array}{l}\text { Accession no. } \\
\mathrm{NSO}_{4} 4856884 \_001\end{array}$} & \multicolumn{2}{|c|}{ Primer Sequence (5' - 3') } \\
\hline & & Forward: & GGCTGCGTCTCTAAGATCCT \\
\hline & & Reverse: & ATTTCCCAGCTGAACATGCC \\
\hline \multirow[t]{2}{*}{ Pax7 } & NSO_4856884_004 & Forward: & TGCCCTCAGTGAGTTCGATT \\
\hline & & Reverse: & CGGGTTCTGACTCCACATCT \\
\hline \multirow[t]{2}{*}{ MYOD } & 8404456555 & Forward: & CCGACGGCATGATGGACTA \\
\hline & & Reverse: & CTCGCTGTAGTAAGTGCGGT \\
\hline \multirow[t]{2}{*}{ MYOG } & 8404456557 & Forward: & CAGTGAATGCAGCTCCCATAG \\
\hline & & Reverse: & GCAGATGATCCCCTGGGTTG \\
\hline \multirow[t]{2}{*}{ MYF4 } & 8404456562 & Forward: & TGGACCCCTTCAGCTACAGA \\
\hline & & Reverse: & ATGCTTGTCCCTCCTTCCTTG \\
\hline \multirow[t]{2}{*}{ MRF5 } & 8404456560 & Forward: & CCCACCTCAAGTTGCTCTGA \\
\hline & & Reverse: & CCGTGGCATATACATTTGGTACA \\
\hline \multirow[t]{2}{*}{$\operatorname{PPAR} \gamma$} & NSE_1498162_016 & Forward: & ATCTGCTGCAAGCCTTGGA \\
\hline & & Reverse: & TGGAGCAGCTTGGCAAAGA \\
\hline \multirow[t]{2}{*}{ C/EBPß } & 840057464 & Forward: & CCAGAAGAAGGTGGAGCAACTG \\
\hline & & Reverse: & TCGGGCAGCGTCTTGAAC \\
\hline \multirow[t]{2}{*}{ SREBP1 } & NSE_1498162_022 & Forward: & CACCGAGGCCAAGTTGAATAA \\
\hline & & Reverse: & CCAGGTCCTTCAGCGATTTG \\
\hline \multirow[t]{2}{*}{ C/EBP $\alpha$} & NSO_5140066_004 & Forward: & ATCGACATCAGCGCCTACAT \\
\hline & & Reverse: & GCCCGGGTAGTCAAAGTCG \\
\hline \multirow[t]{2}{*}{$\mathrm{ACC}$} & 8405780950 & Forward: & СТCСАACСТCAАCCACTACGG \\
\hline & & Reverse: & GGGGAATCACAGAAGCAGCC \\
\hline \multirow[t]{2}{*}{ FAS } & 8405780945 & Forward: & TAAGGTTCAAATTGCTGCGT \\
\hline & & Reverse: & TCCAGAGCGAAGGAGAGATT \\
\hline \multirow[t]{2}{*}{ CPT1 } & 84044456553 & Forward: & ACACATCTACCTGTCCGTGATCA \\
\hline & & Reverse: & CCCCTGAGGATGCCATTCT \\
\hline
\end{tabular}




\begin{tabular}{llll} 
SCD & NSE_1498162_019 & Forward: & TGCCCACCACAAGTTTTCAG \\
& & Reverse: & GCCAACCCACGTGAGAGAAG \\
AMPK $\alpha$ & \multirow{2}{*}{ 8404456568 } & Forward: & CACCAAGGTGTAAGGAAAGCA \\
& & Reverse: & ACGGGTTTACAACCTTCCATTC \\
LPL & NSE_1498162_015 & Forward: & ACGATTATTGCTCAGCATGG \\
& & Reverse: & ACTTTGTACAGGCACAACCG \\
GPR43 & NSO_5189193 & Forward: & GGCTTTCCCCGTGCAGTA \\
& & Reverse: & ATCAGAGCAGCGATCACTCCAT \\
FABP4 & AJ_4160220 & Forward: & AAACTTAGATGAAGGTGCTCTGG \\
& & Reverse: & CATAAACTCTGGTGGCAGTGA \\
PLIN2 & NSO_5379931 & Forward: & GCGTCTGCTGGCTGATTTCT \\
& & Reverse: & TGTAAGCCGAGGAGACCAGA \\
GAPDH & NSO_4761240 & Forward: & ACTCTGGCAAAGTGGATGTTGTC \\
& & Reverse: & GCATCACCCCACTTGATGTTG \\
\hline
\end{tabular}

Pax3, Paired box 3; Pax7, Paired box 7; MYOD, myogenic differentiation-1; MYOG, myogenin; MYF4, myogenin-4; MRF5, myogenic regulatory factor-5; PPAR, peroxisome proliferator-activated receptor gamma; $C / E B P \beta, C C A A T /$ enhancer-binding protein beta;

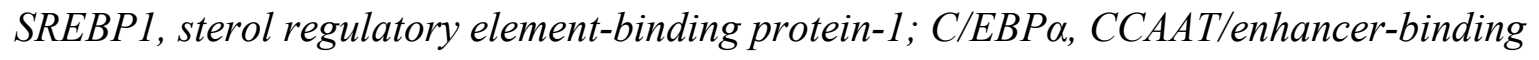
protein alpha; ACC, acetyl-coenzyme A carboxylase; FAS, fatty acid synthetase; CPT1, carnitine palmitoyltransferase; SCD, stearoyl-coenzyme A desaturase; $A M P K \alpha$, adenosine 5 '-monophosphate-activated protein kinase; LPL, lipoprotein lipase; GPR43, G protein-coupled receptor-43; FABP4, fatty acid binding protein-4; PLIN2, perilipin-2; GAPDH, glyceraldehyde-3-phosphate dehydrogenase. 
Table 2. Number of DEGs after treatment with different concentrations of ciglitazone

\begin{tabular}{cccc}
\hline Type & $\mathrm{CL}$ & $\mathrm{CM}$ & $\mathrm{CH}$ \\
\hline Up & 609 & 562 & 501 \\
Down & 508 & 526 & 432 \\
Total & 1117 & 1088 & 933 \\
\hline
\end{tabular}



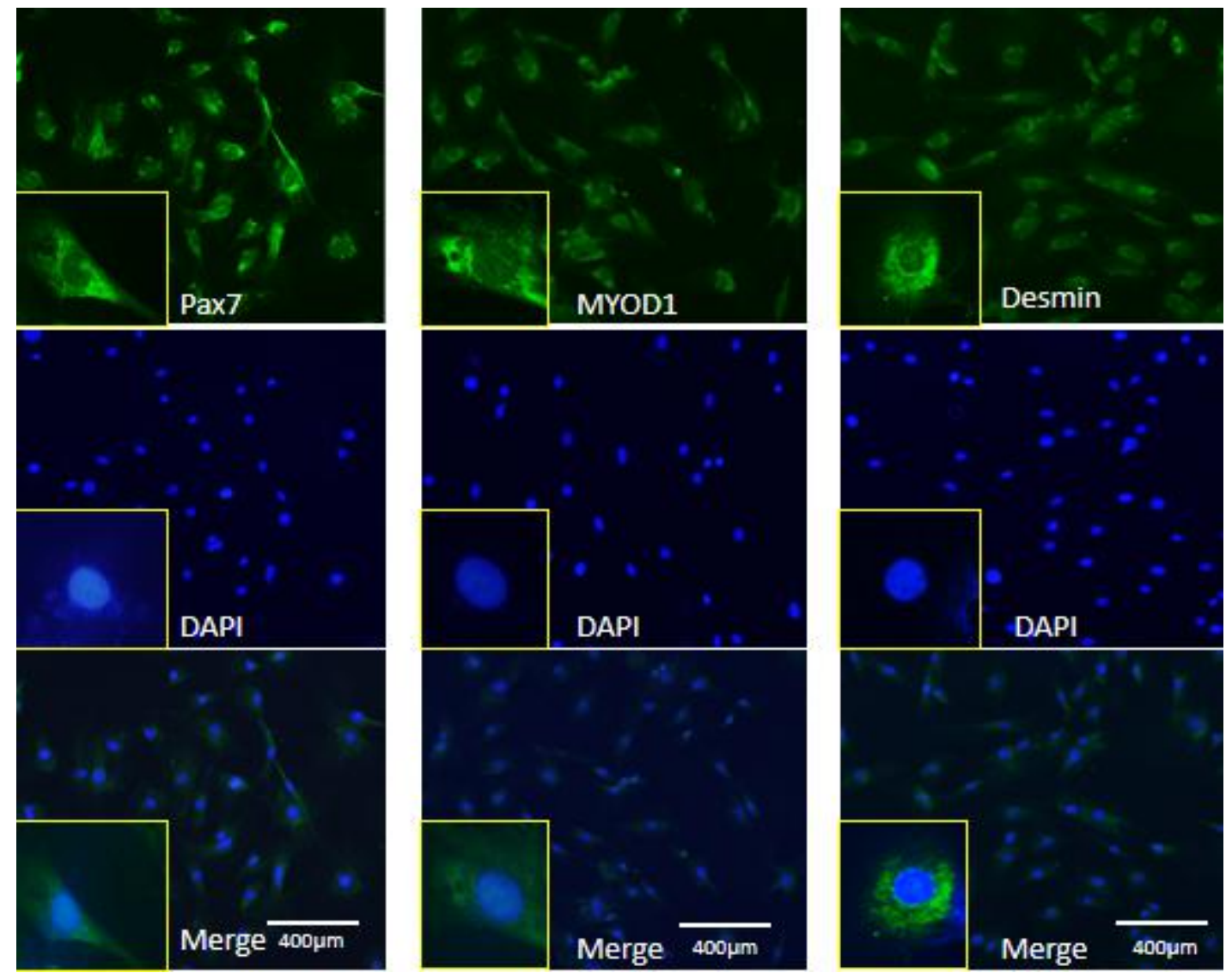

Figure 1 

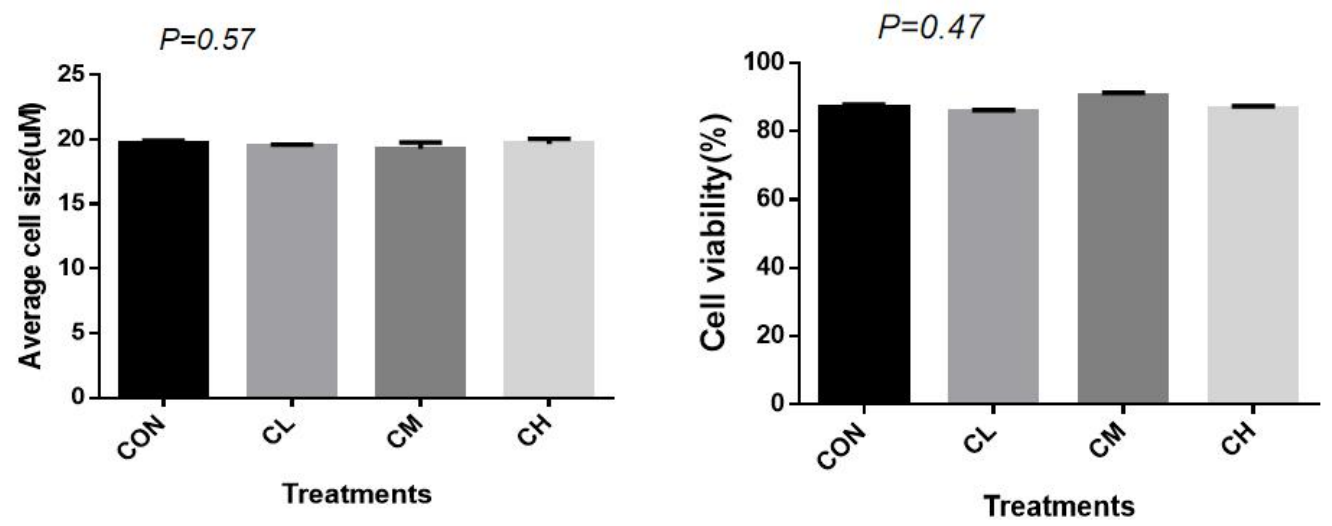

Figure 2 

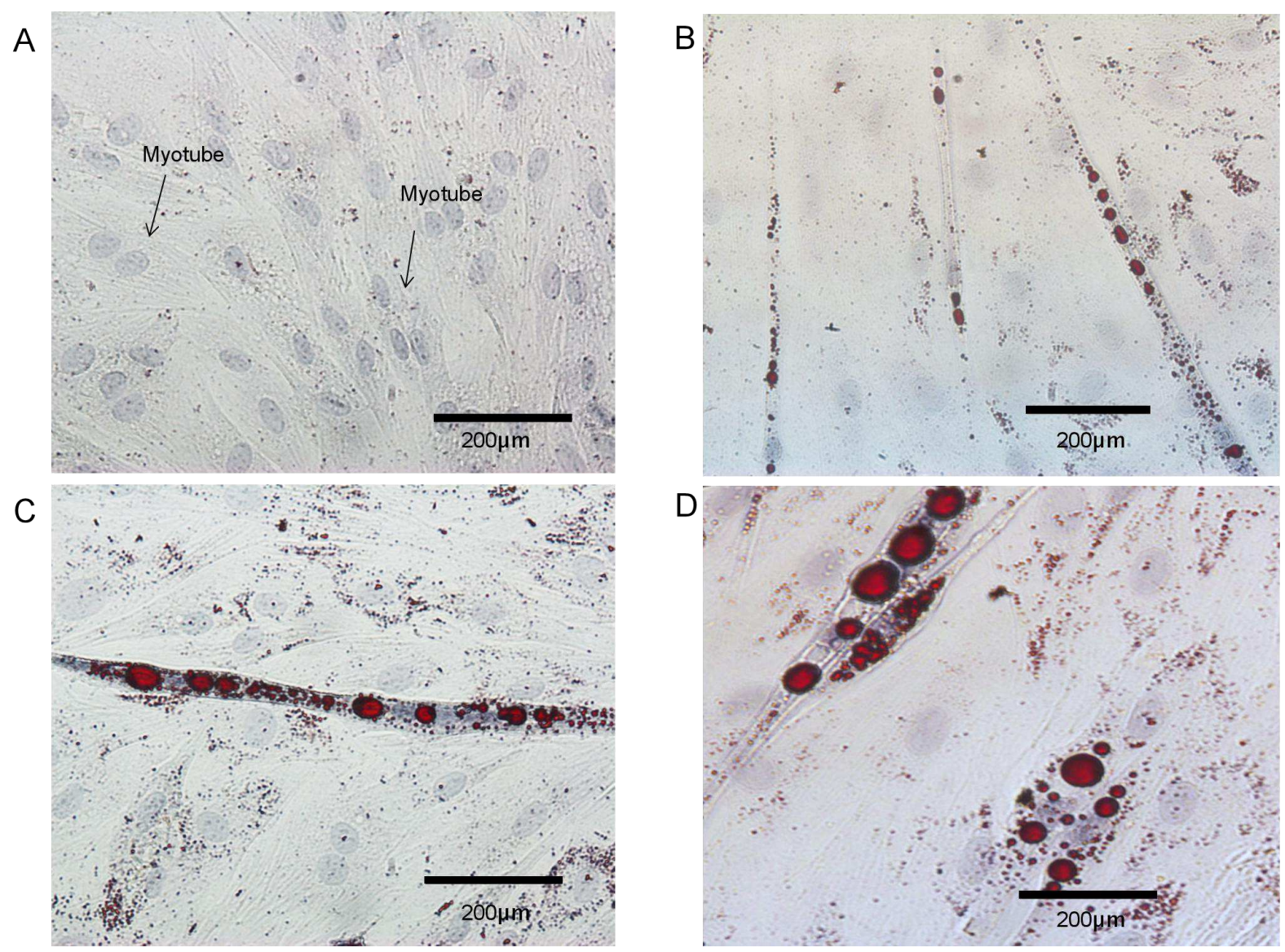

Figure 3 

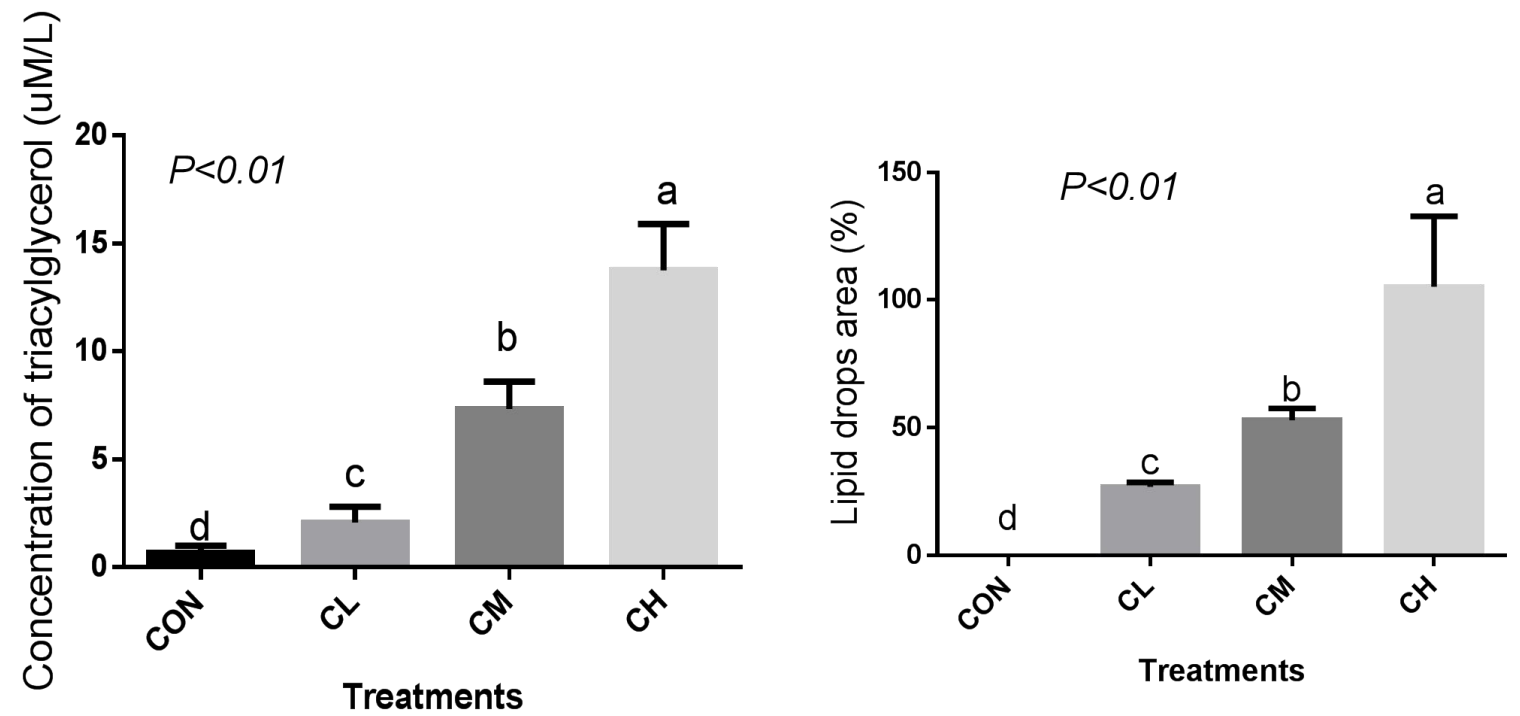

Figure 4 

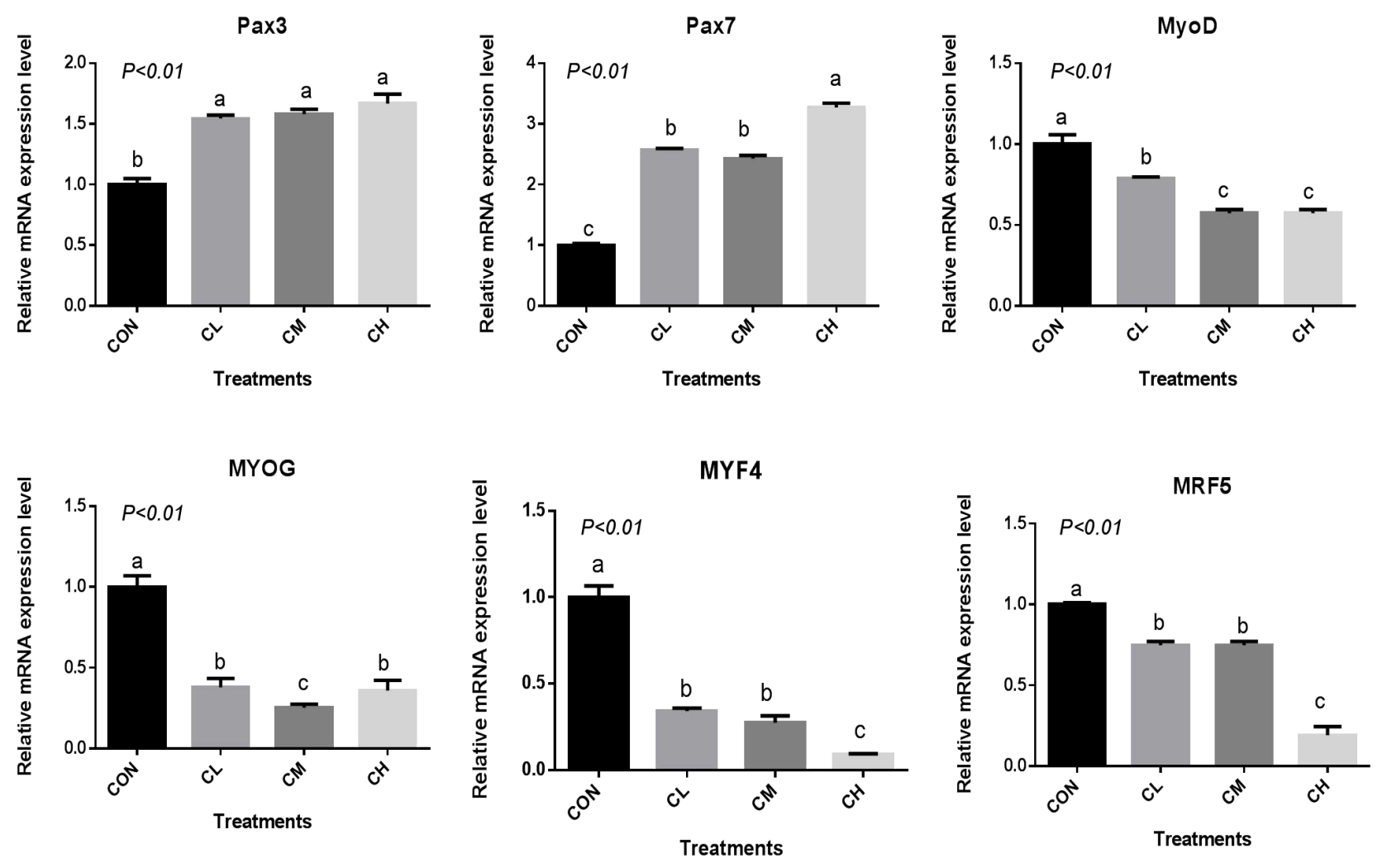

Figure 5 

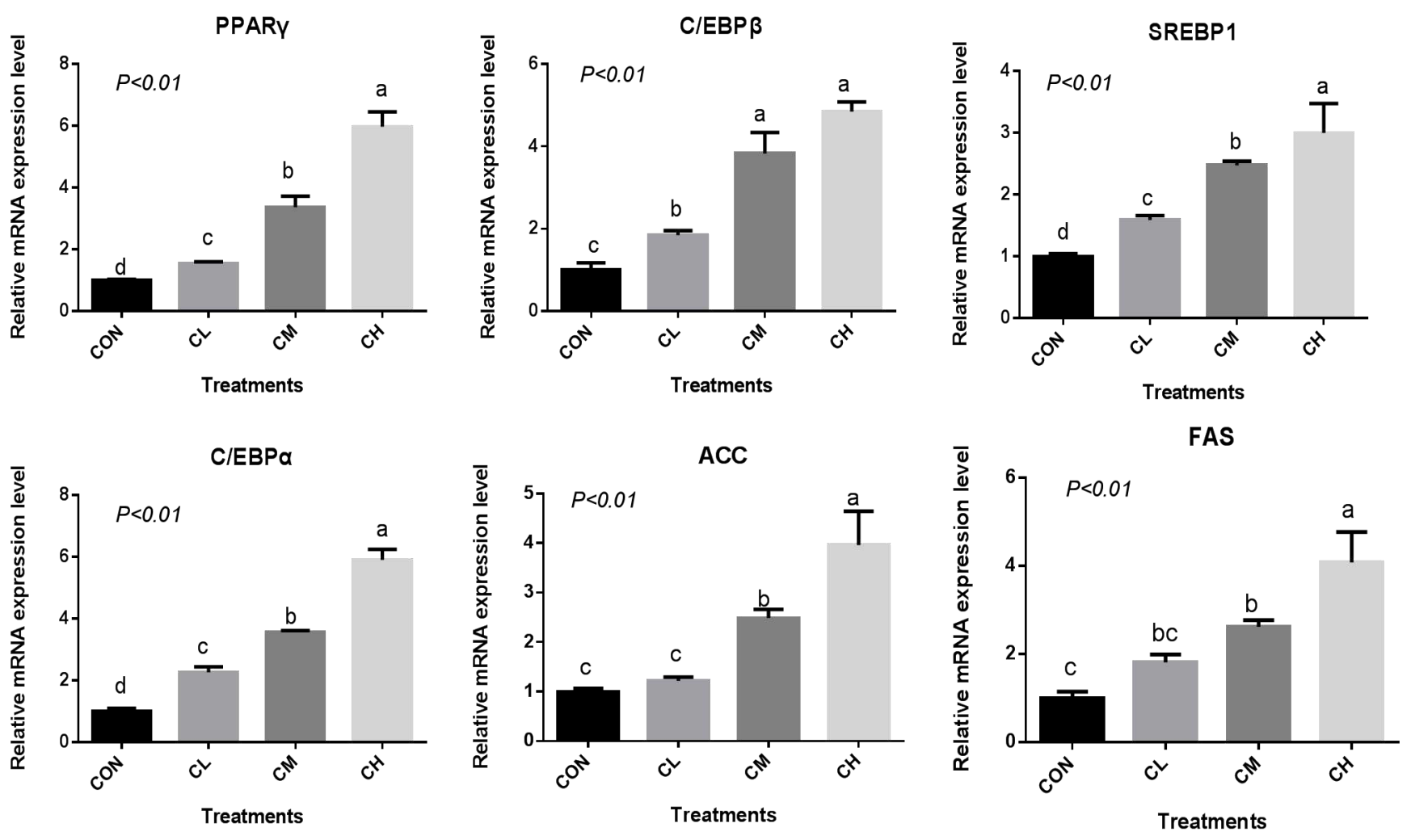

Figure 6 

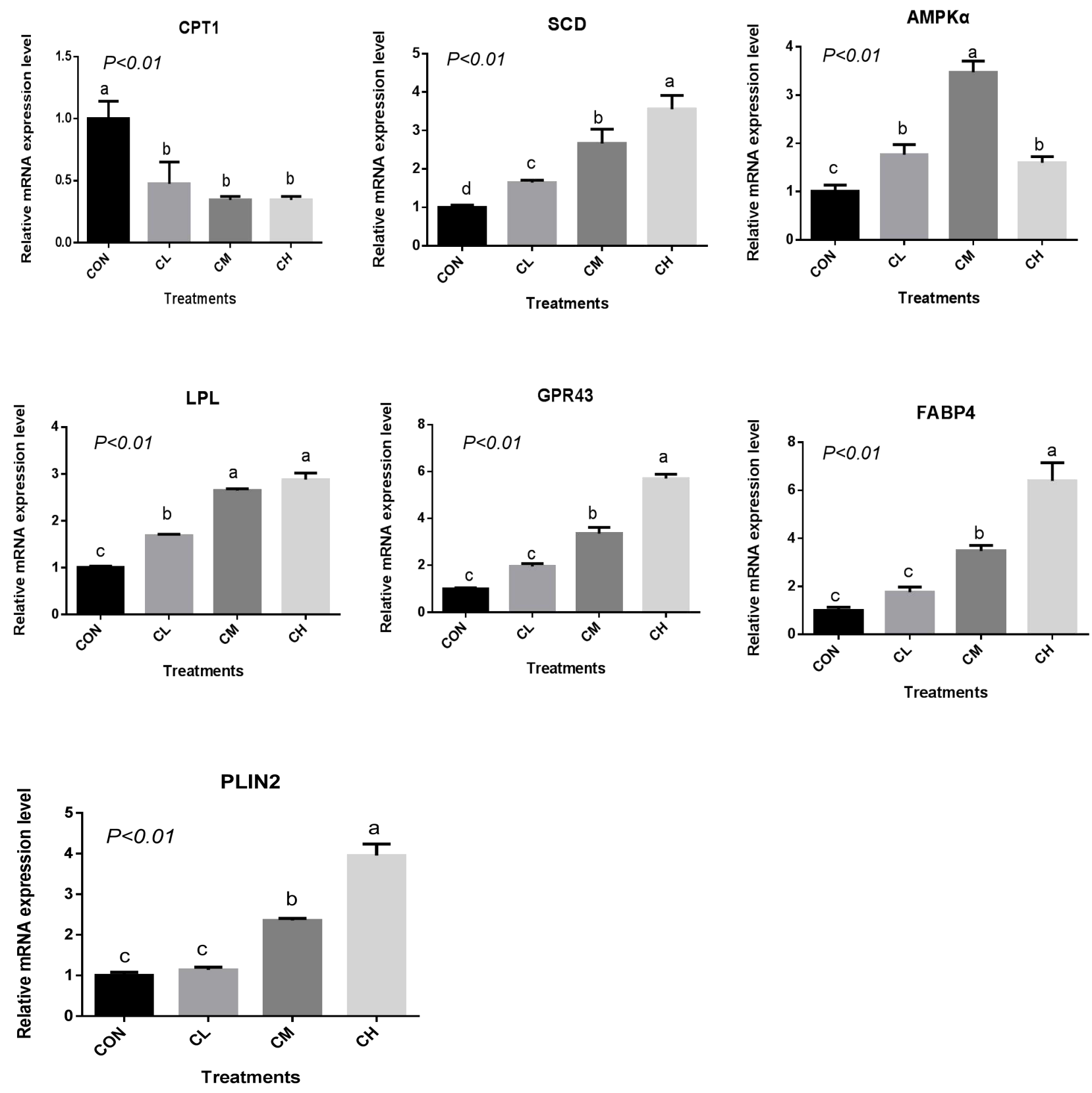

Figure 7 


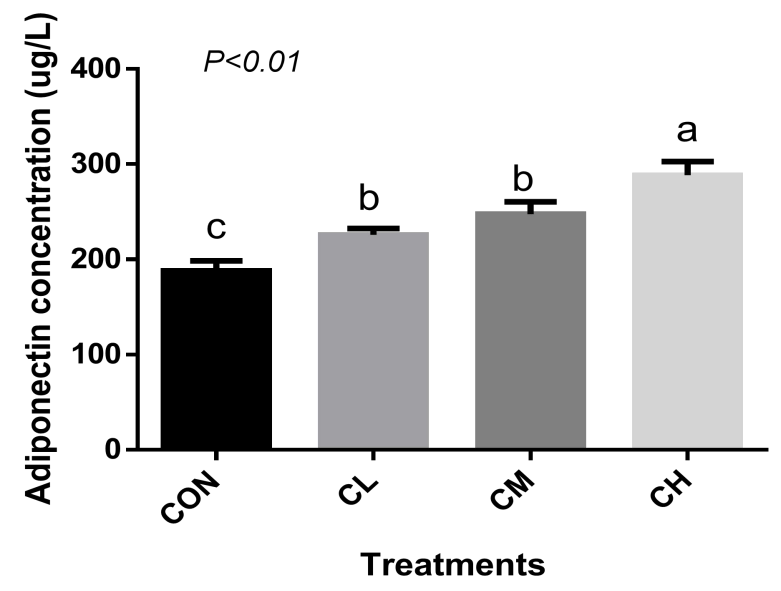

Figure 8 

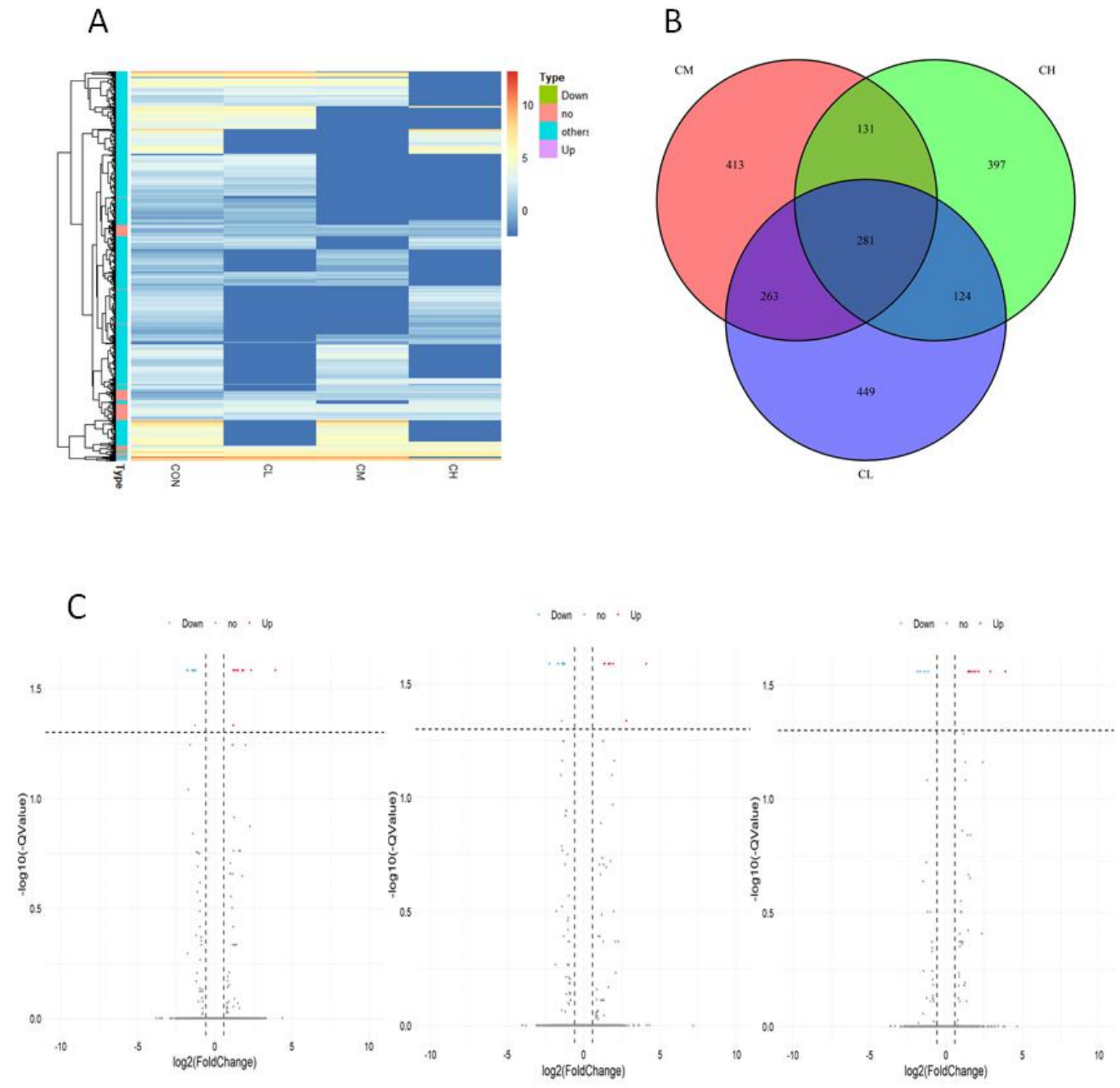

Figure 9 
CON-CL
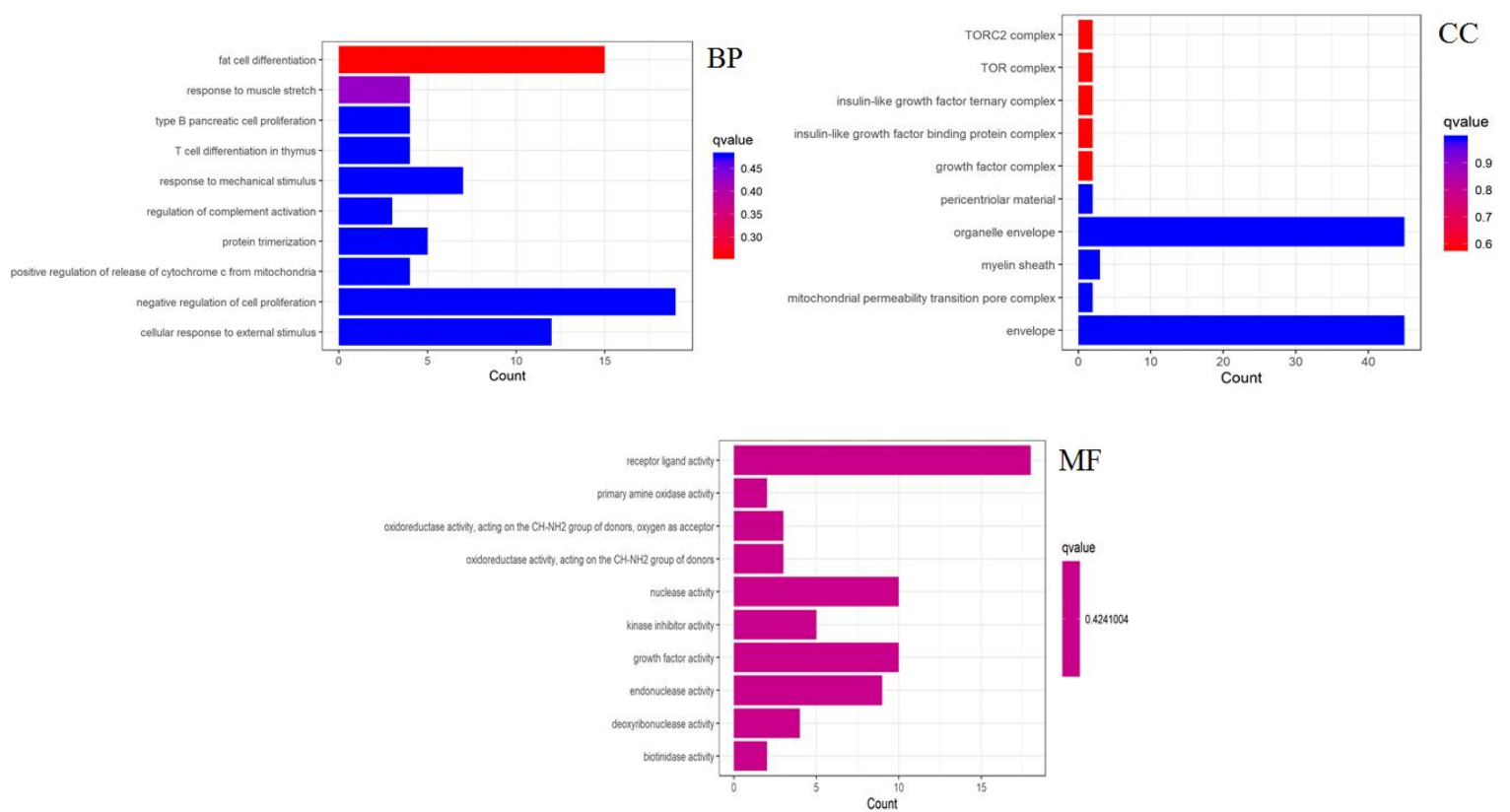

CON-CM
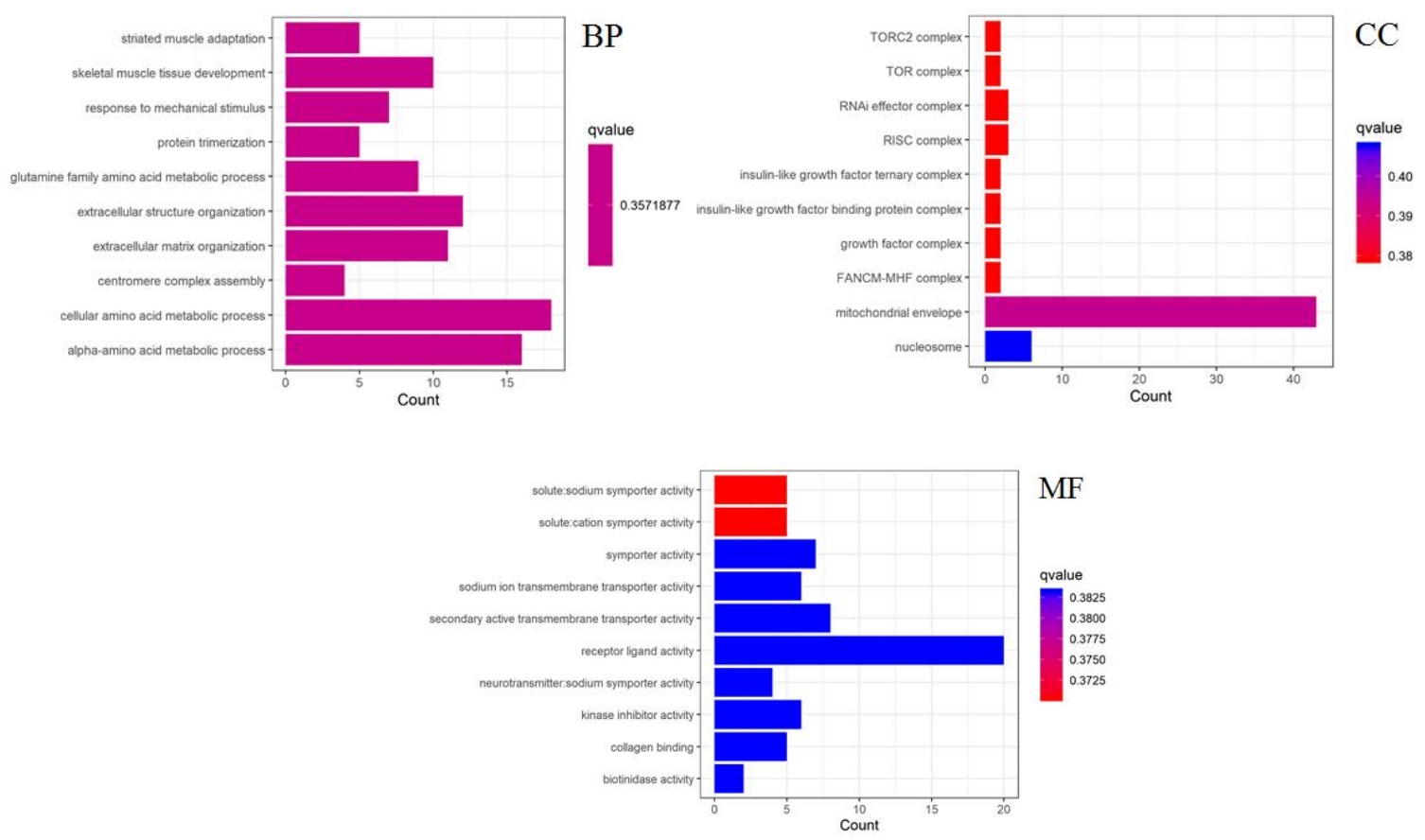
$\mathrm{CON}-\mathrm{CH}$
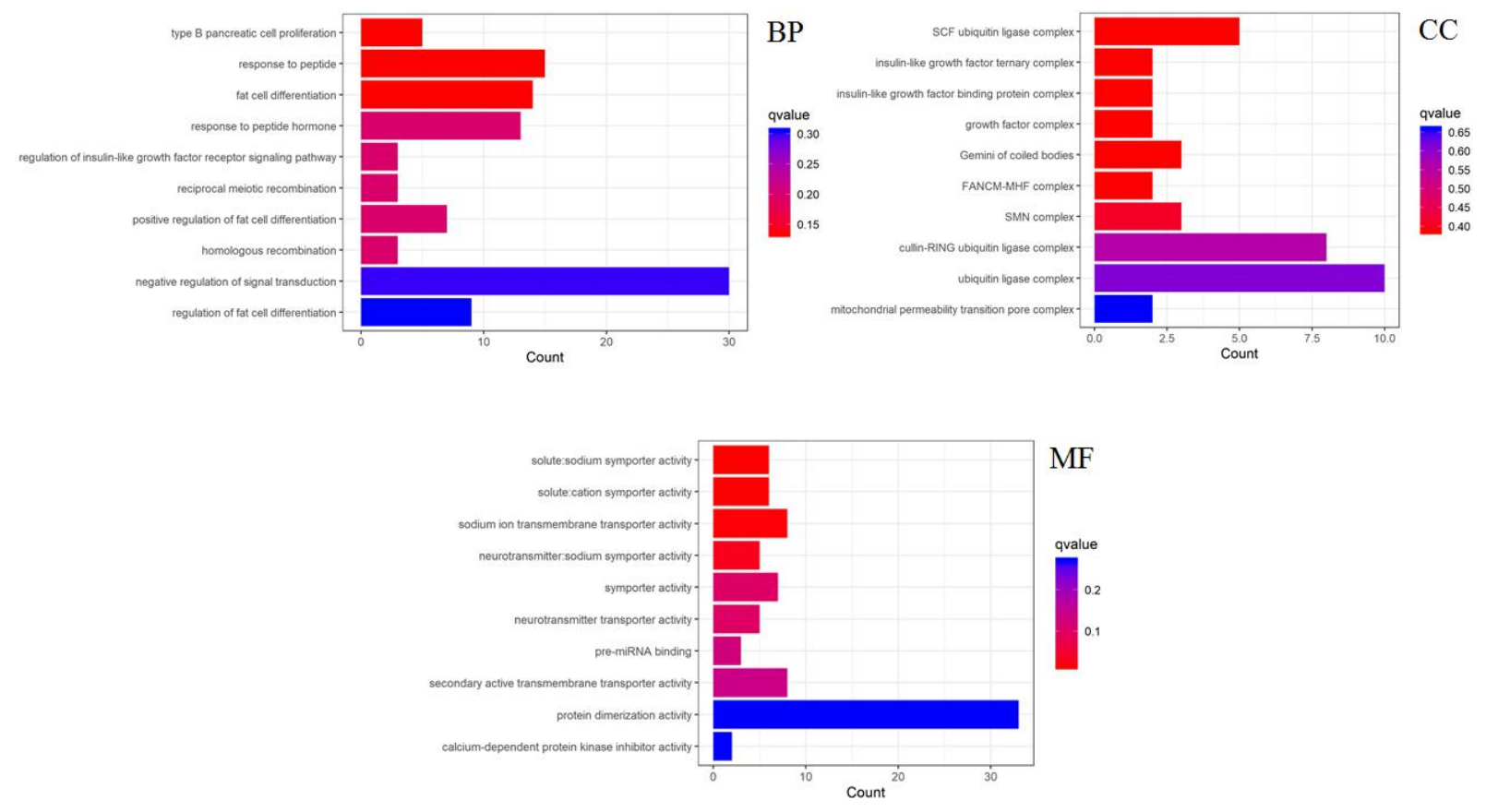

Figure 10 


\section{CON-CL}

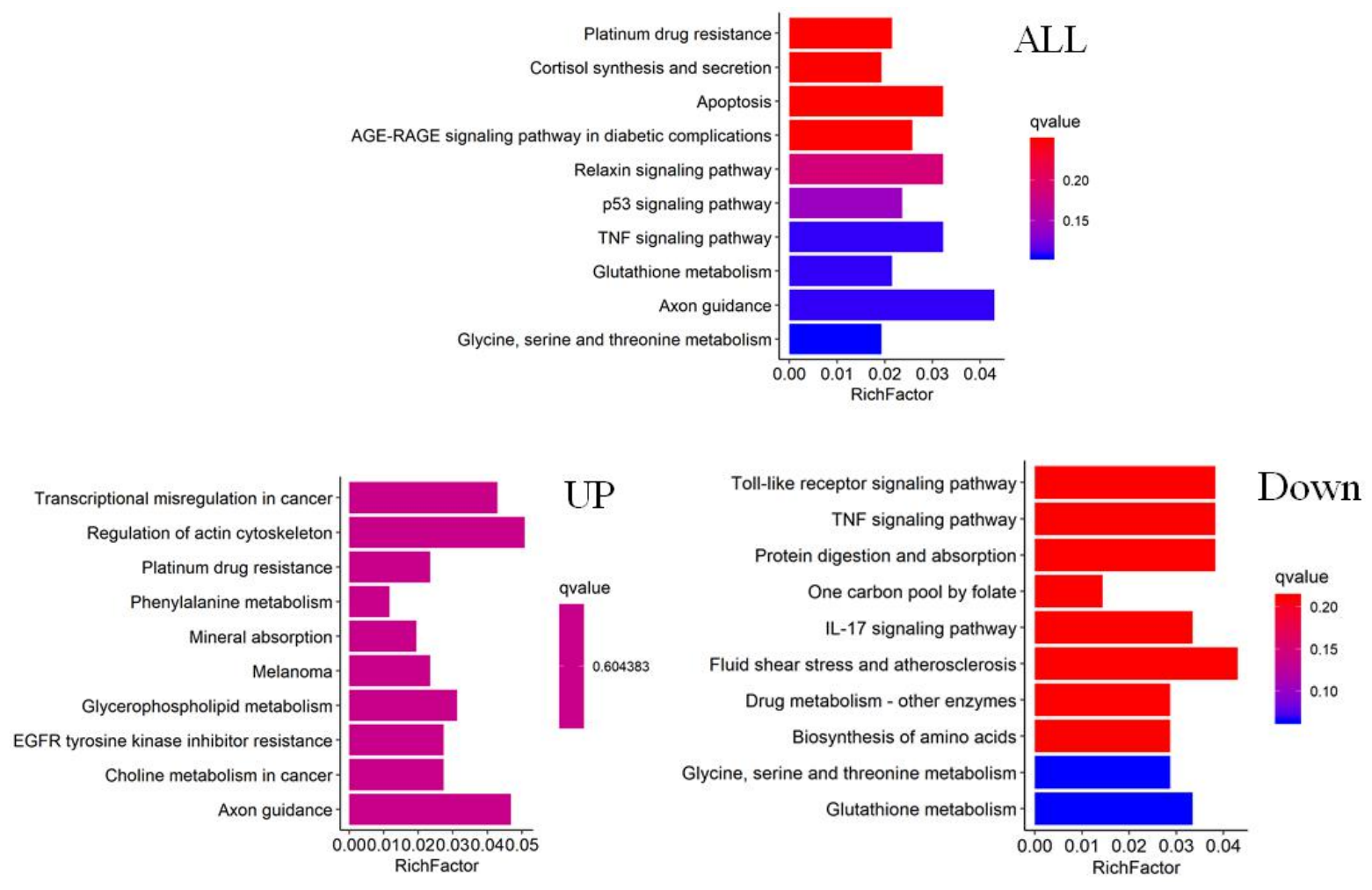

\section{$\mathrm{CON}-\mathrm{CM}$}

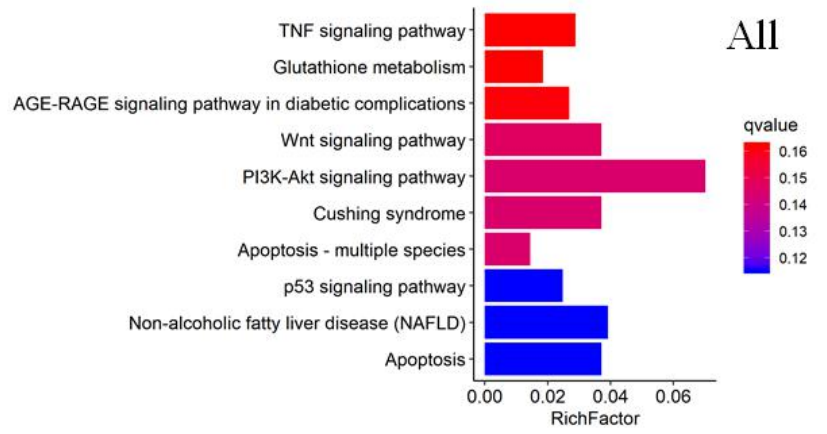




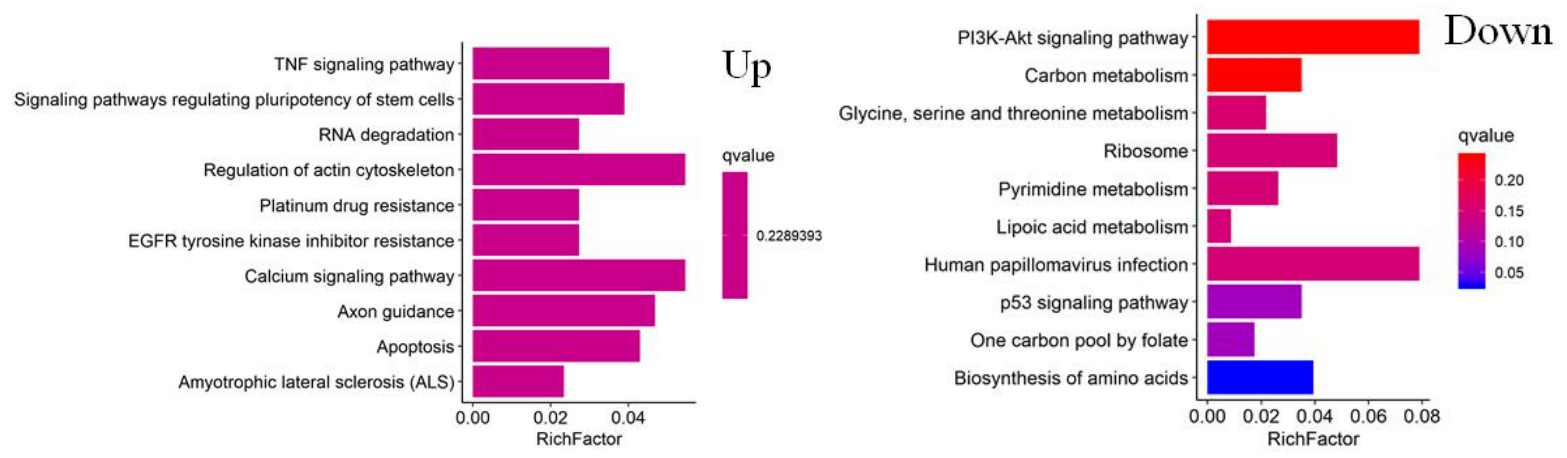

\section{$\mathrm{CON}-\mathrm{CH}$}
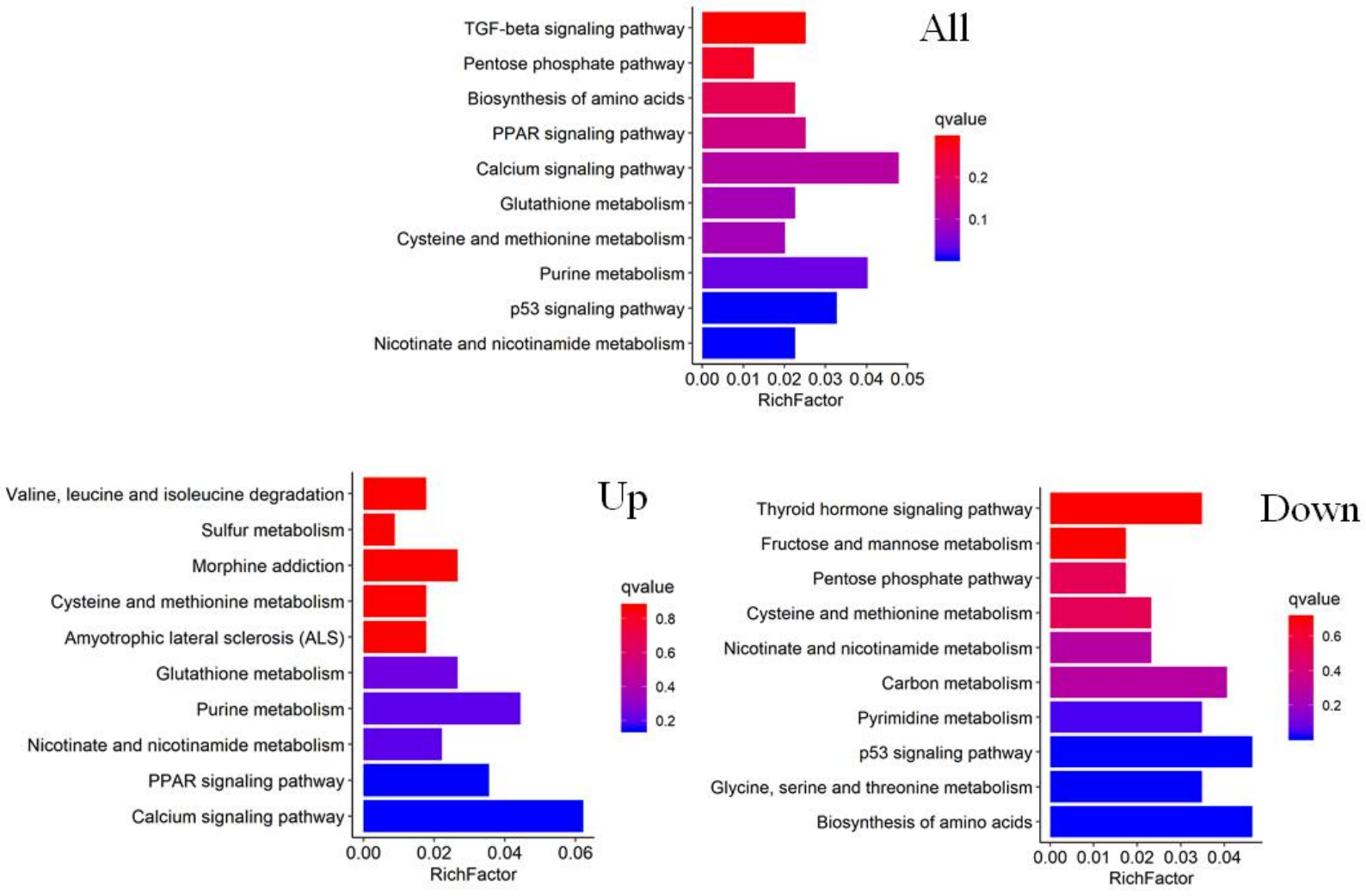

Figure 11 


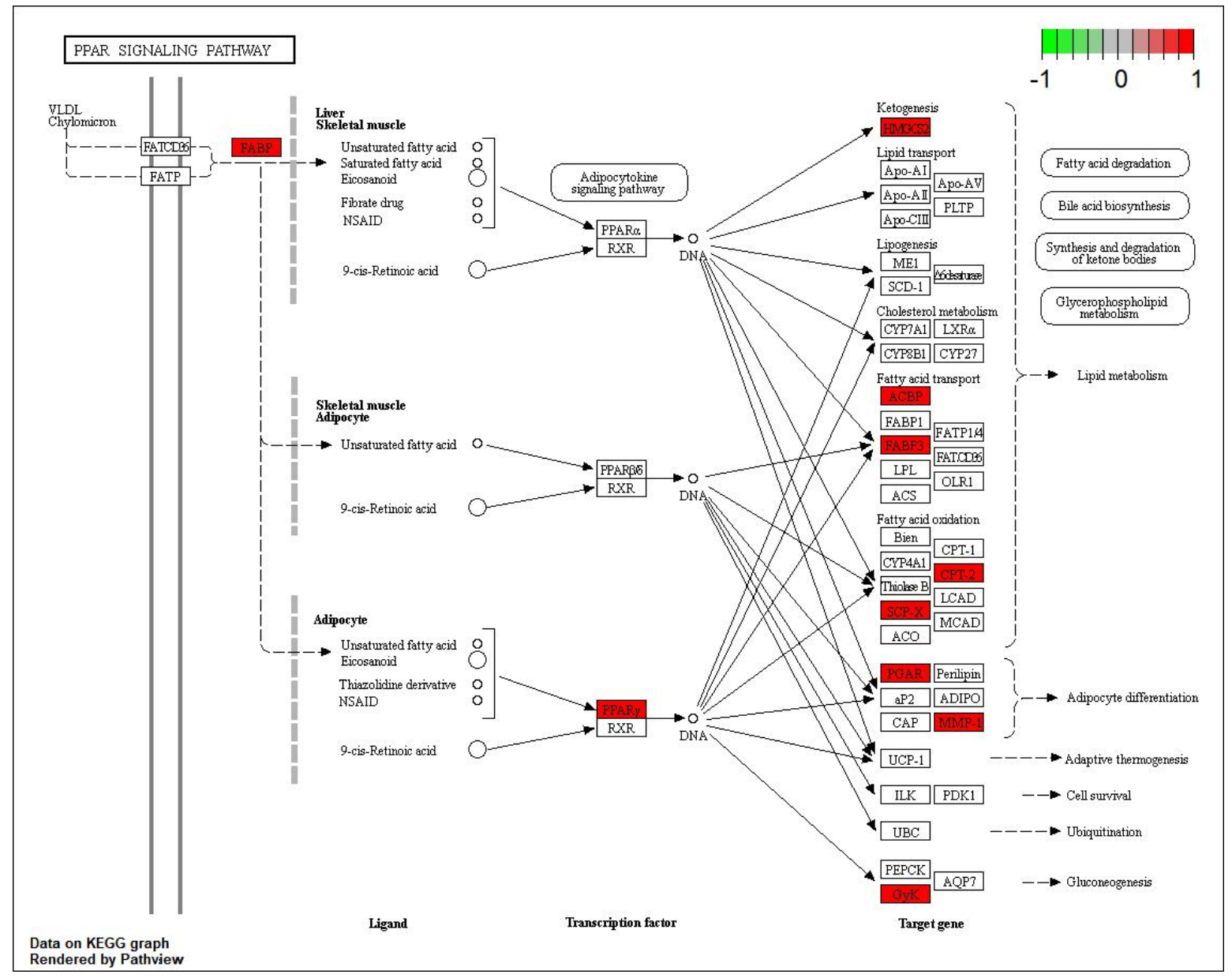

Figure 12 


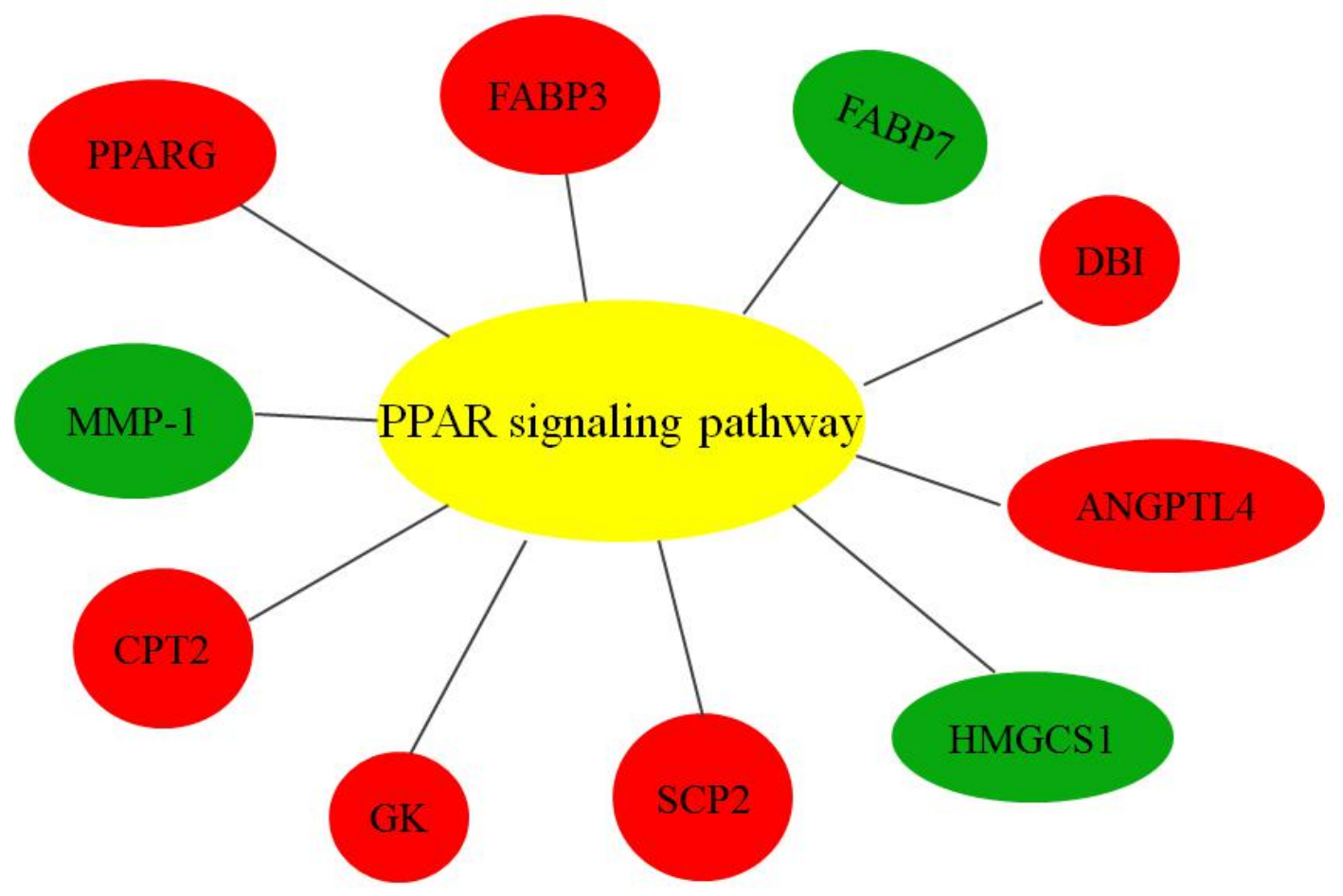

Figure 13 
Figures
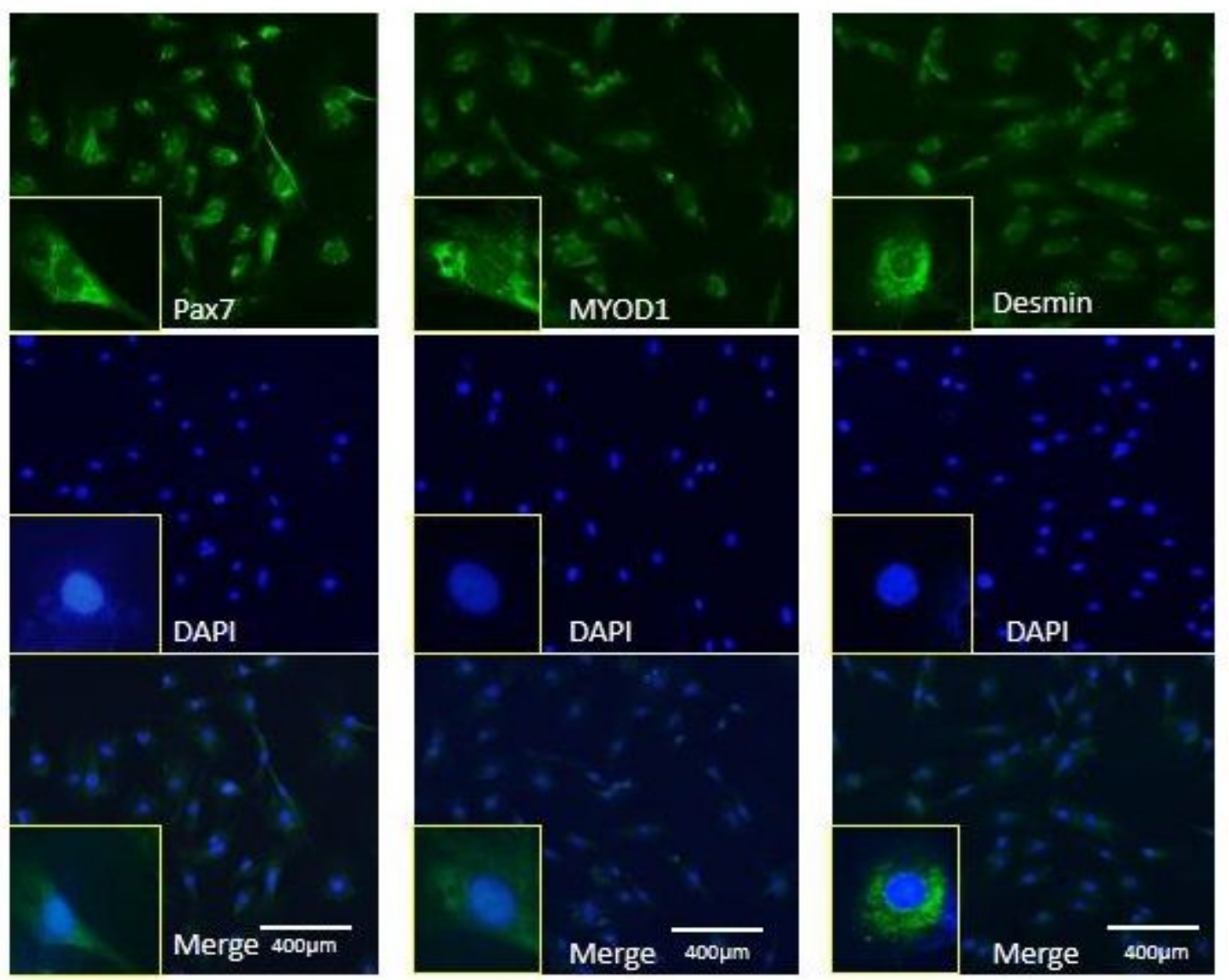

Figure 1

Immunofluorescence staining showed that the nucleus after DAPI staining was blue, and Pax7 (a), MYOD1 (b) and Desmin (c) were green in the cytoplasm. The original magnification was $40 \times$ (scale bars $=200 \mu \mathrm{m})$. Results represent three independent experiments.

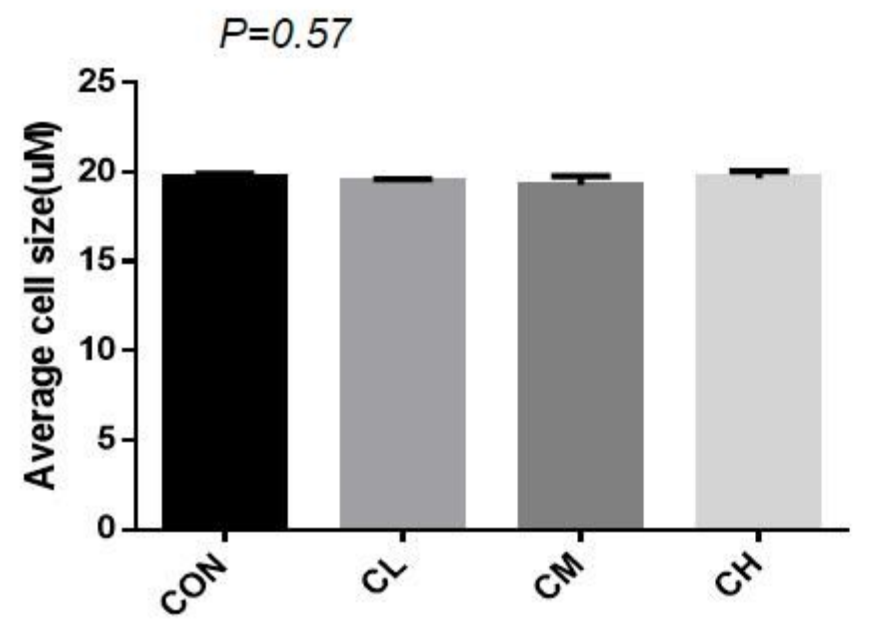

Treatments

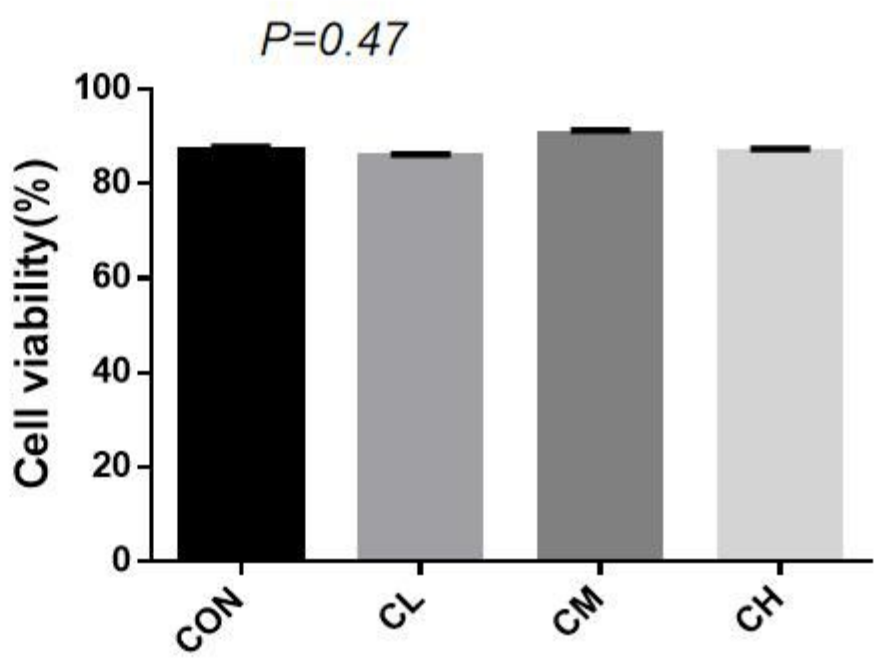

Treatments 


\section{Figure 2}

Effects of ciglitazone on average cell size and cell viability in BSC after $96 \mathrm{~h}$ in culture. CON, DMEM $+2 \%$ horse serum (I); $\mathrm{CL}, \mathrm{CON}+5 \mu \mathrm{M}$ ciglitazone; $\mathrm{CM}, \mathrm{CON}+10 \mu \mathrm{M}$ ciglitazone; $\mathrm{CH}, \mathrm{CON}+20 \mu \mathrm{M}$ ciglitazone. Values are means of 6 culture dishes derived from six animals. a,b,c Means within a panel with common superscripts are not different $(P>0.05)$.
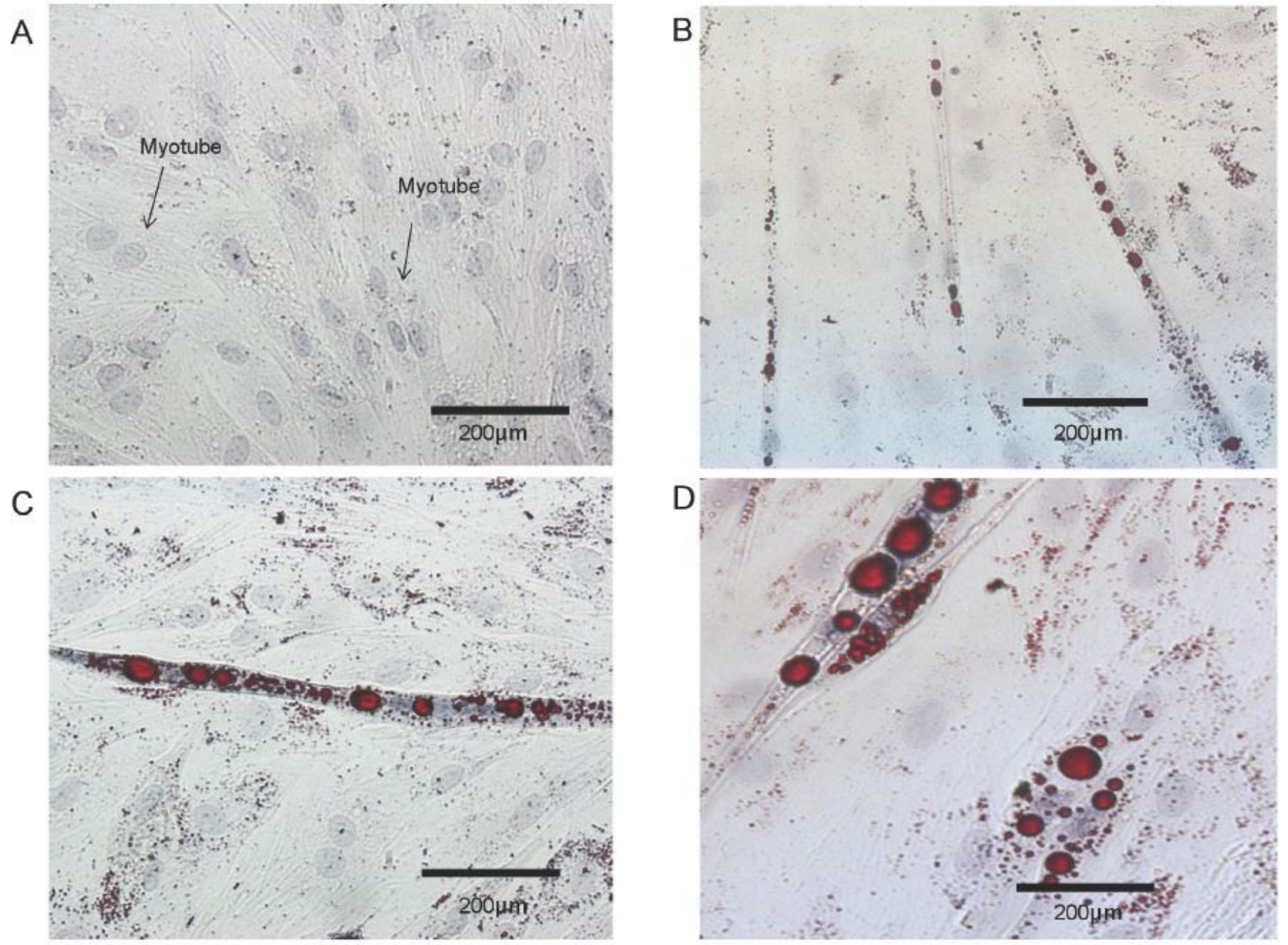

\section{Figure 3}

Oil Red O- and hematoxylin-stained bovine satellite cells (BSC) cultured with ciglitazone in Dulbecco's modified Eagle's medium (I) containing $2 \%$ horse serum after $96 \mathrm{~h}$ culture. A, CON (DMEM $+2 \%$ horse serum); $\mathrm{B}, \mathrm{CL}(\mathrm{CON}+5 \mu \mathrm{M}$ ciglitazone); $\mathrm{C}, \mathrm{CM}(\mathrm{CON}+10 \mu \mathrm{M}$ ciglitazone); $\mathrm{D}, \mathrm{CH}(\mathrm{CON}+20 \mu \mathrm{M}$ ciglitazone). Scale bars $=200 \mu \mathrm{m}$. 

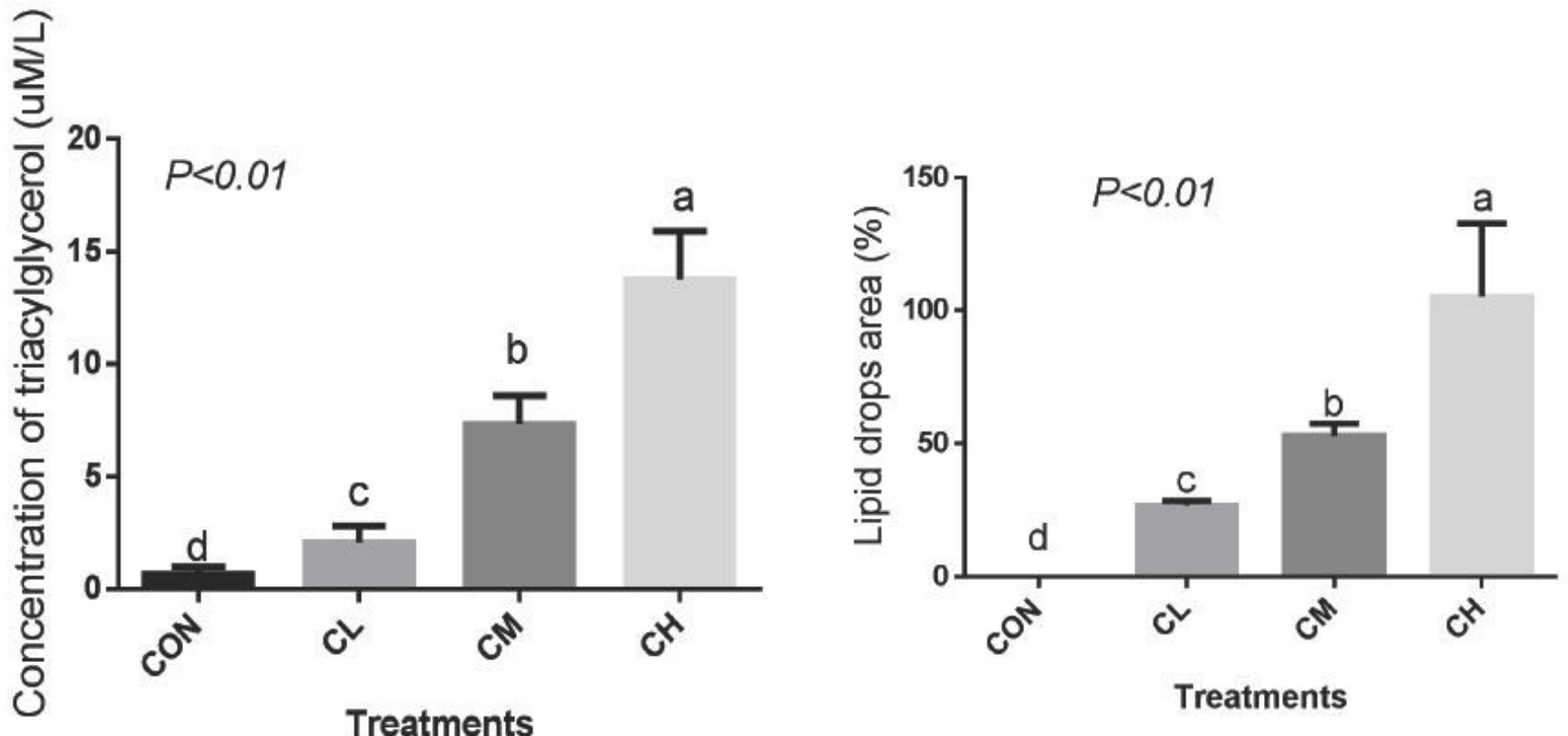

Figure 4

Effect of ciglitazone on triacylglycerol and percent lipid droplet area in BSC after $96 \mathrm{~h}$ of culture. CON, $\mathrm{DMEM}+2 \%$ horse serum; $\mathrm{CL}, \mathrm{CON}+5 \mu \mathrm{M}$ ciglitazone; $\mathrm{CM}, \mathrm{CON}+10 \mu \mathrm{M}$ ciglitazone; $\mathrm{CH}, \mathrm{CON}+20 \mu \mathrm{M}$ ciglitazone. Error bars are mean \pm S.E. The letters $a, b, c$, and $d$ indicate a significant difference $(P<0.01)$ within an item compared with undifferentiated cells. The results are representative of six independent experiments. 

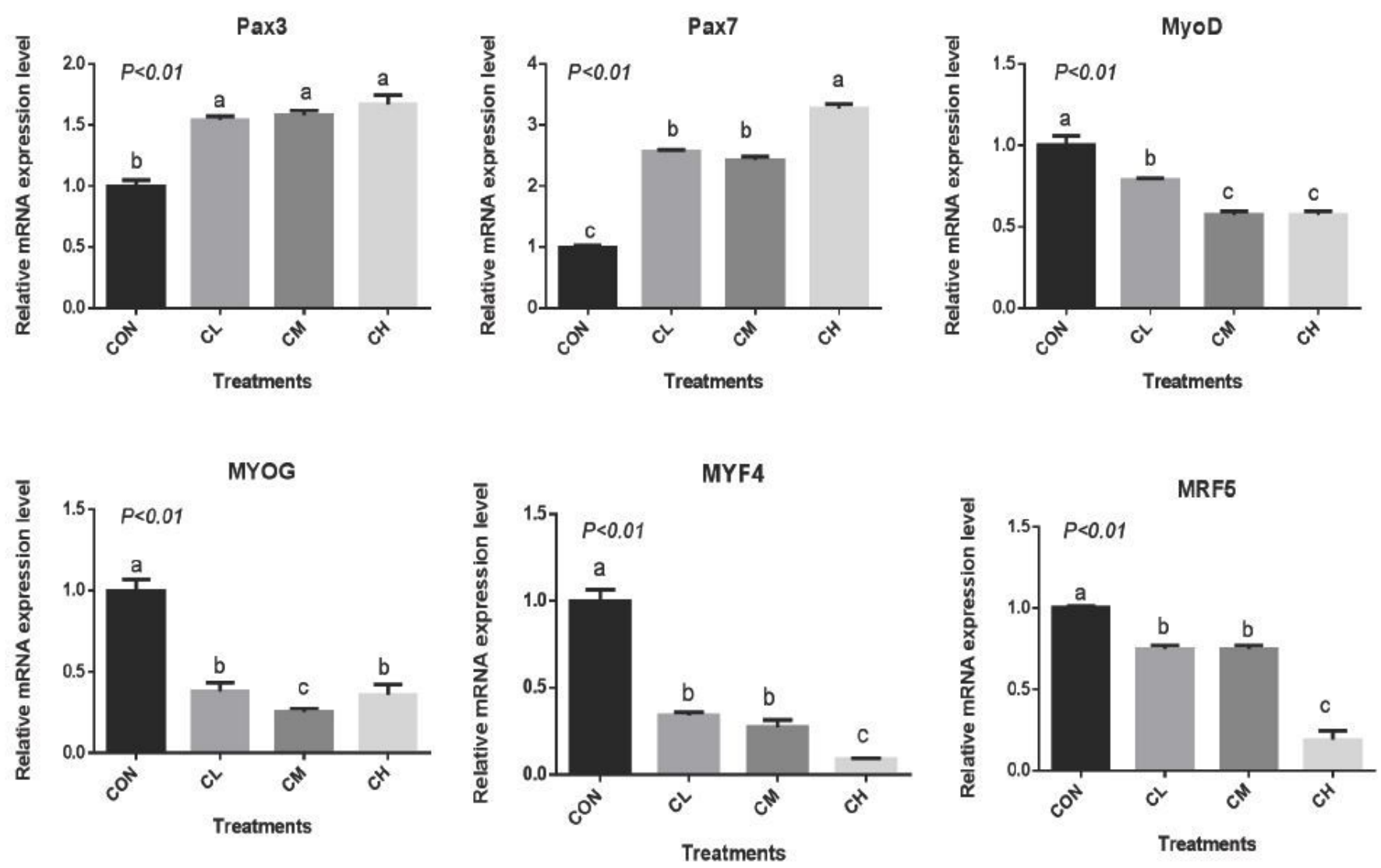

\section{Figure 5}

Myogenic gene expression: Pax3, Pax7, MYOD, MYOG, MYF4 and MRF5 gene expression in BSC cultured with ciglitazone in Dulbecco's modified Eagle medium containing $2 \%$ horse serum after $96 \mathrm{~h}$ of incubation. CON, DMEM + 2\% horse serum; $\mathrm{CL}, \mathrm{CON}+5 \mu \mathrm{M}$ ciglitazone; $\mathrm{CM}, \mathrm{CON}+10 \mu \mathrm{M}$ ciglitazone; $\mathrm{CH}$, $\mathrm{CON}+20 \mu \mathrm{M}$ ciglitazone. The results of gene expression were consistent with protein expression. The bars are the means $\pm S E$. The letters $a, b, c$, and $d$ indicate a significant difference $(P<0.01)$ within an item compared with undifferentiated cells. The results are representative of six independent experiments. 

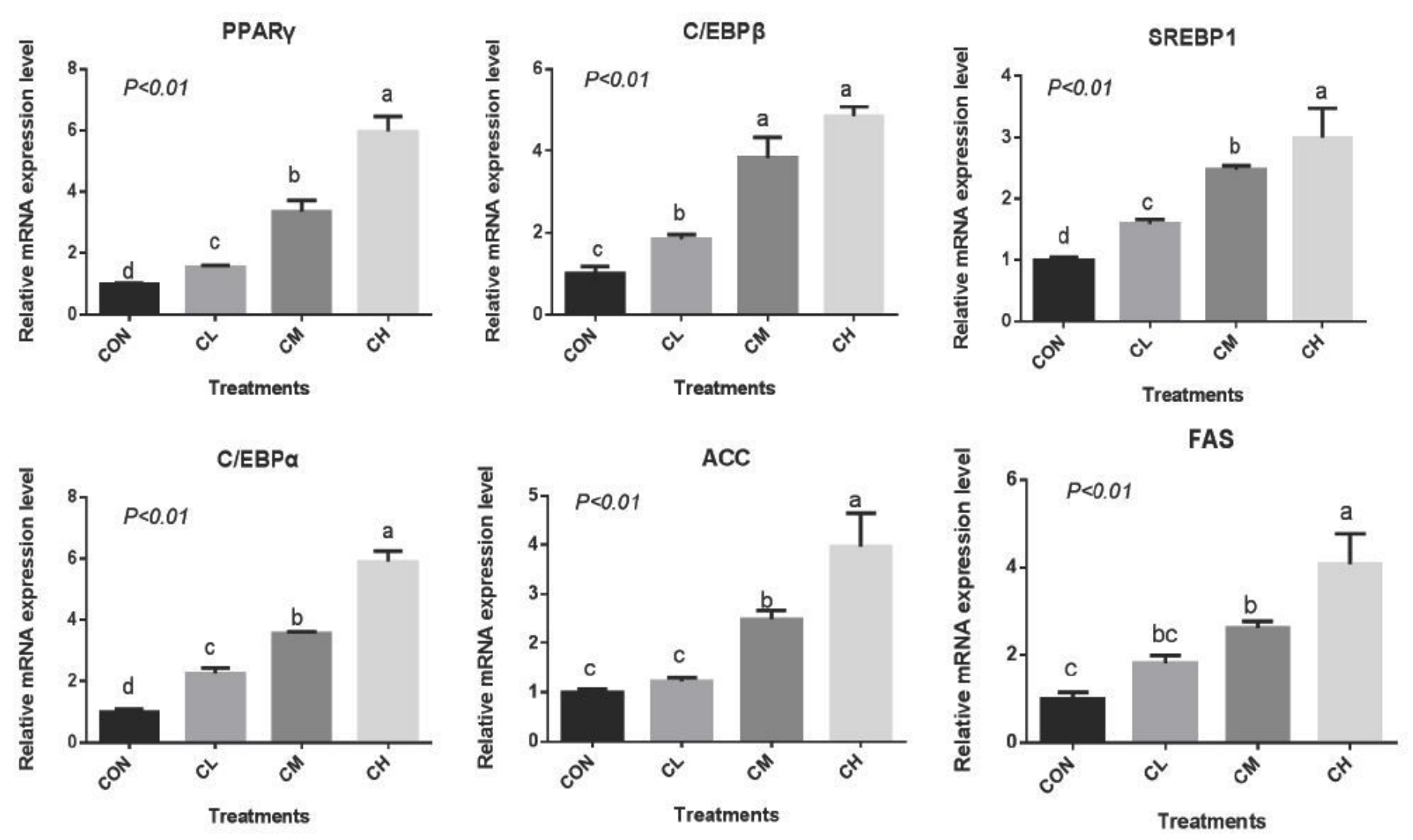

Figure 6

Adipogenic gene expression: PPARy, C/EBP 3 , SREBP1, C/EBPa, ACC, FAS gene expression in BSC cultured with ciglitazone in Dulbecco's modified Eagle medium containing $2 \%$ horse serum after $96 \mathrm{~h}$ of incubation. $\mathrm{CON}, \mathrm{DMEM}+2 \%$ horse serum; $\mathrm{CL}, \mathrm{CON}+5 \mu \mathrm{M}$ ciglitazone; $\mathrm{CM}, \mathrm{CON}+10 \mu \mathrm{M}$ ciglitazone; $\mathrm{CH}$, $\mathrm{CON}+20 \mu \mathrm{M}$ ciglitazone. The results of gene expression were consistent with protein expression. Error bars are the means $\pm S E$. The letters $a, b, c$, and $d$ indicate a significant difference $(P<0.01)$ within an item compared with undifferentiated cells. The results are representative of six separate experiments. 

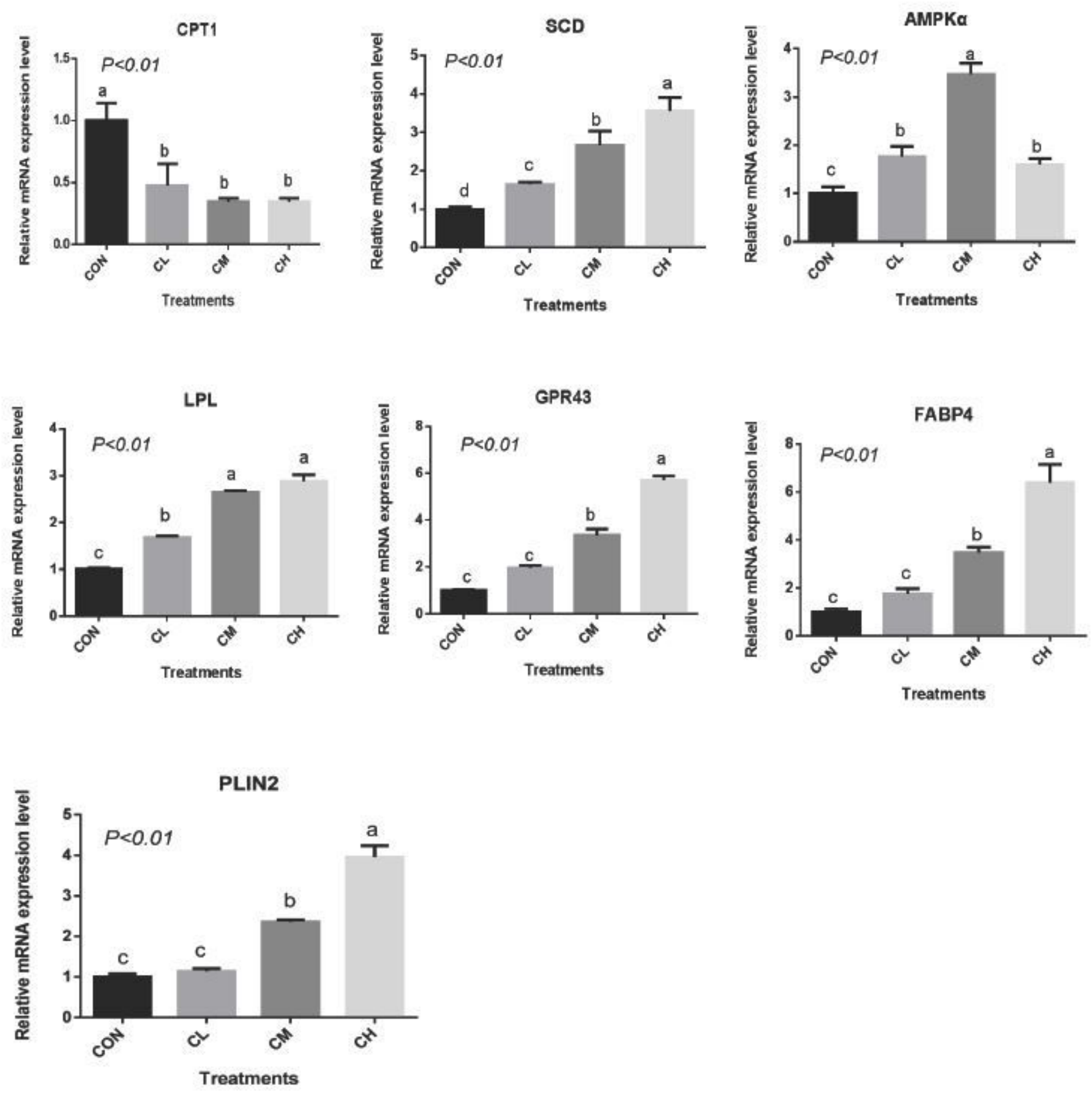

Figure 7

Gene Expression Associated with lipid metabolism $₫ \mathrm{CPT} 1$, SCD, AMPKa, LPL, GPR43, FABP4, PLIN2 gene expression in BSC cultured with ciglitazone in Dulbecco's modified Eagle medium (I) containing $2 \%$ horse serum at $96 \mathrm{~h}$ incubation time. CON, DMEM + 2\% horse serum; $\mathrm{CL}, \mathrm{CON}+5 \mu \mathrm{M}$ ciglitazone; $\mathrm{CM}, \mathrm{CON}+10$ $\mu \mathrm{M}$ ciglitazone; $\mathrm{CH}, \mathrm{CON}+20 \mu \mathrm{M}$ ciglitazone. The results of gene expression were consistent with protein expression. The bars are the means \pm SE. The letters $a, b, c$, and $d$ indicate a significant difference $(P<$ 
$0.01)$ within an item compared with undifferentiated cells. The results are representative of six independent experiments.

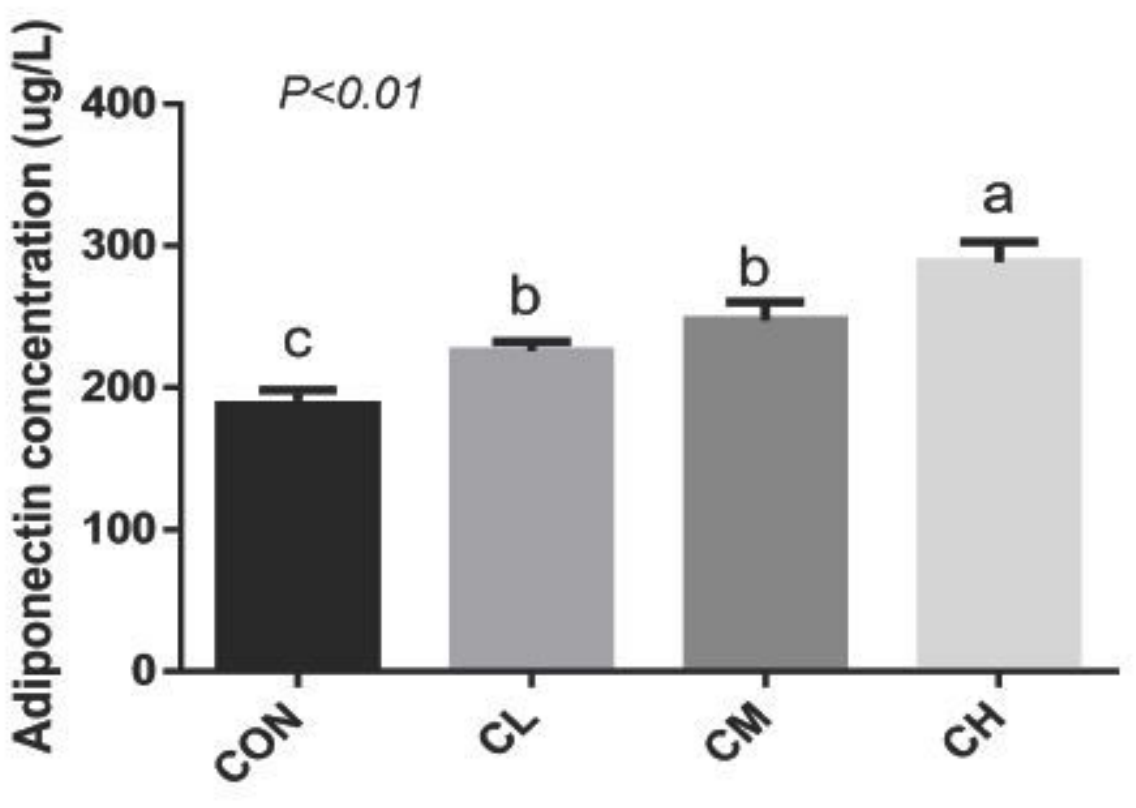

Treatments

\section{Figure 8}

Adiponectin concentration $(\mu \mathrm{g} / \mathrm{mL})$ in media from BSC cultured for $96 \mathrm{~h}$ with ciglitazone in Dulbecco's modified Eagles medium containing $2 \%$ horse serum at $96 \mathrm{~h}$ incubation time. CON, DMEM $+2 \%$ horse serum; $\mathrm{CL}, \mathrm{CON}+5 \mu \mathrm{M}$ ciglitazone; $\mathrm{CM}, \mathrm{CON}+10 \mu \mathrm{M}$ ciglitazone; $\mathrm{CH}, \mathrm{CON}+20 \mu \mathrm{M}$ ciglitazone. The bars are the mean $s \pm S E$. The letters $a, b, c$, and d indicate a significant difference $(P<0.01)$ within an item compared with undifferentiated cells. The results are representative of six independent experiments. 

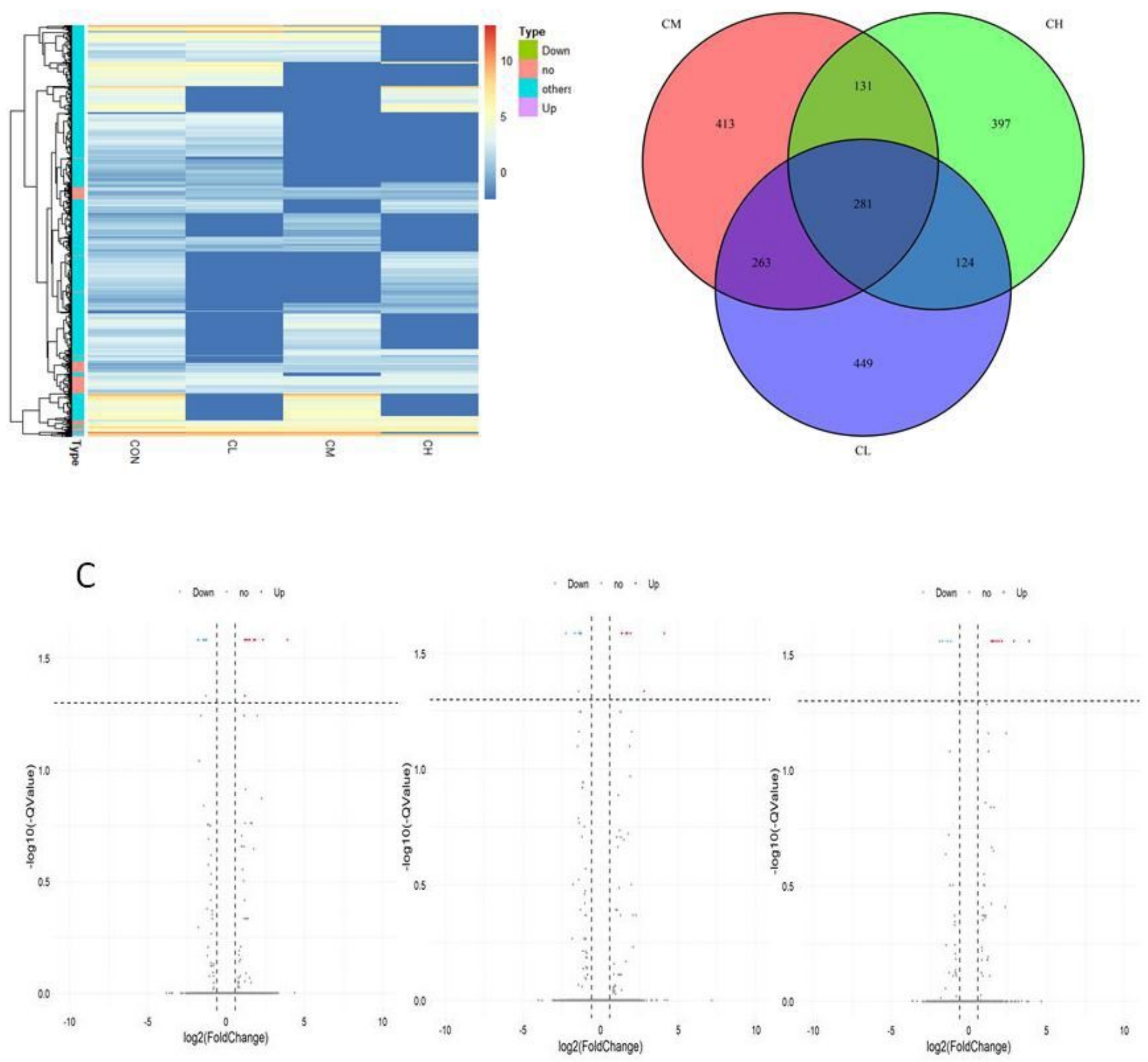

\section{Figure 9}

Differentially Expressed Genes (A) Heatmap for the Figure hierarchical cluster analysis of differentially expressed genes (DEGs) after differentiation of BSC in Yanbian Yellow Cattle with different concentrations of ciglitazone.(B) Wayne map and (C) Volcano Plot. Red represents up regulated genes and blue represents down-regulated genes. $\mathrm{CON}, \mathrm{DMEM}+2 \%$ horse serum; $\mathrm{CL}, \mathrm{CON}+5 \mu \mathrm{M}$ ciglitazone; $\mathrm{CM}, \mathrm{CON}+10 \mu \mathrm{M}$ ciglitazone; $\mathrm{CH}, \mathrm{CON}+20 \mu \mathrm{M}$ ciglitazone . 
CON-CL

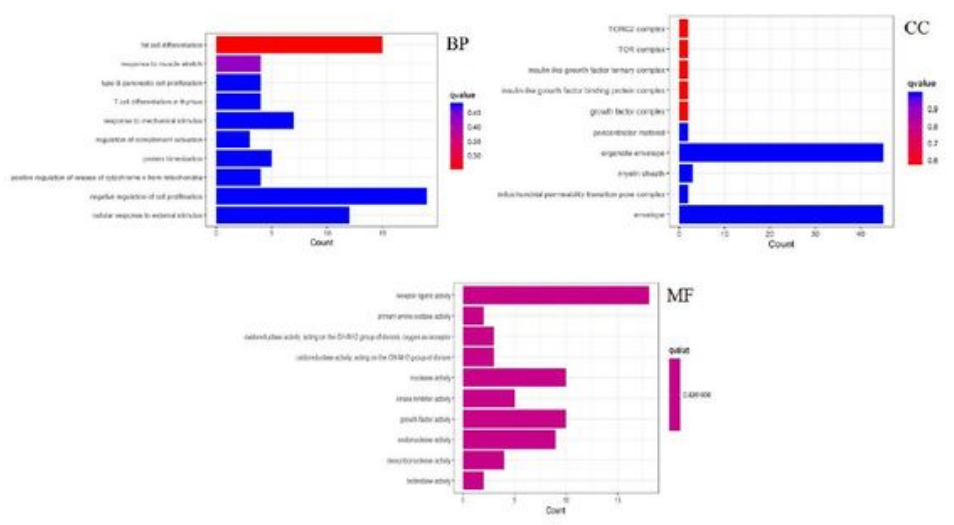

CON-CM
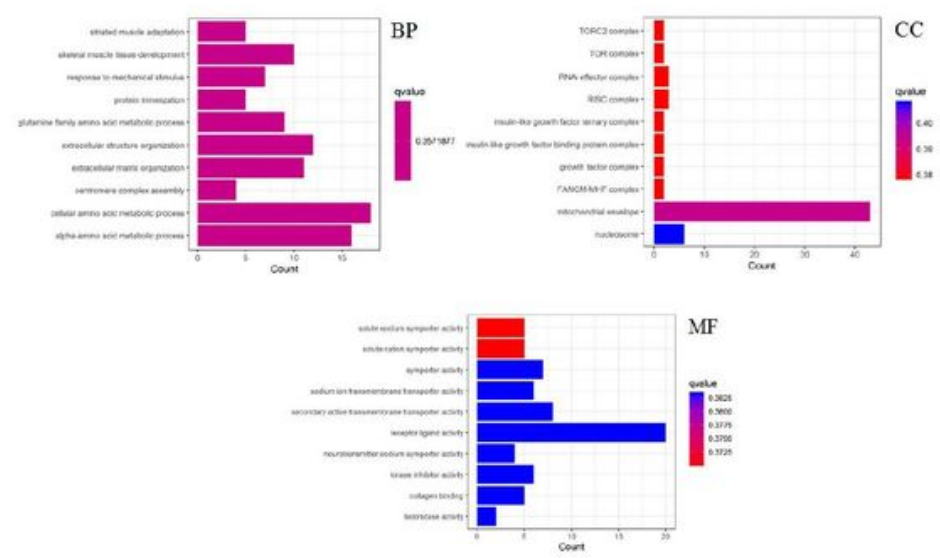

CON-CH
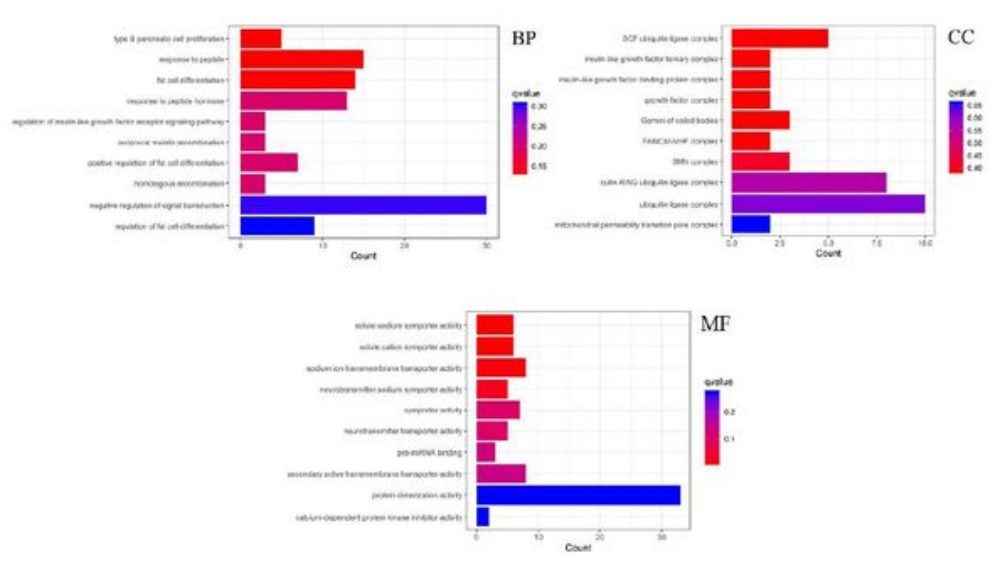

Figure 10

Gene Ontology (GO) classification of differentially expressed genes (DEGs) after differentiation of BSC in Yanbian Yellow Cattle with different concentrations of ciglitazone. CON, DMEM $+2 \%$ horse serum; CL, $\mathrm{CON}+5 \mu \mathrm{M}$ ciglitazone; $\mathrm{CM}, \mathrm{CON}+10 \mu \mathrm{M}$ ciglitazone; $\mathrm{CH}, \mathrm{CON}+20 \mu \mathrm{M}$ ciglitazone. 

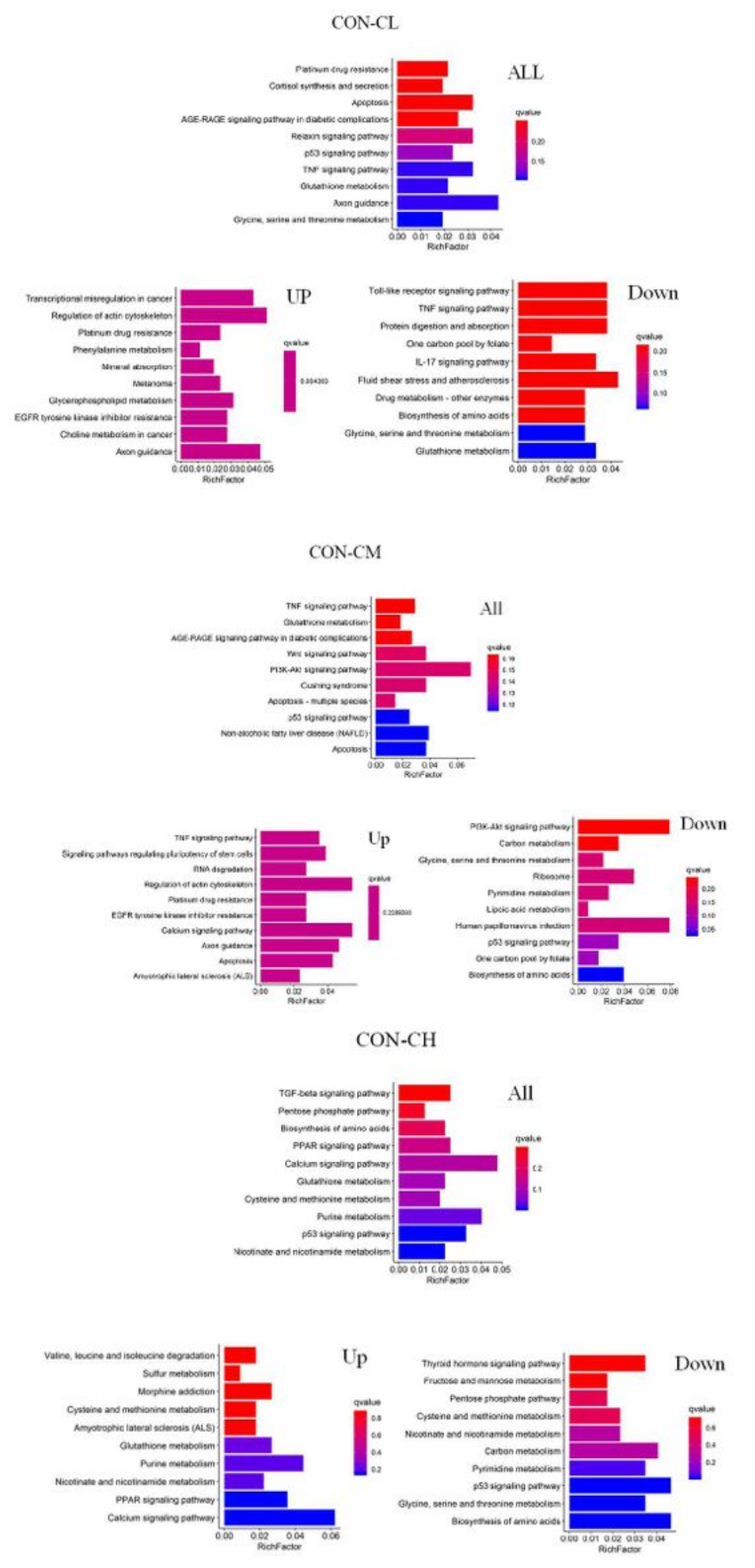

\section{Figure 11}

KEGG functional enrichment of transcriptome from skeletal muscle satellite cells of different doses of ciglitazone. CON, DMEM + 2\%HS; CON-CL, CON + $5 \mu \mathrm{M}$ ciglitazone; CON-CM: CON + $10 \mu \mathrm{M}$ ciglitazone; $\mathrm{CON}-\mathrm{CH}, \mathrm{CON}+20 \mu \mathrm{M}$ ciglitazone. 


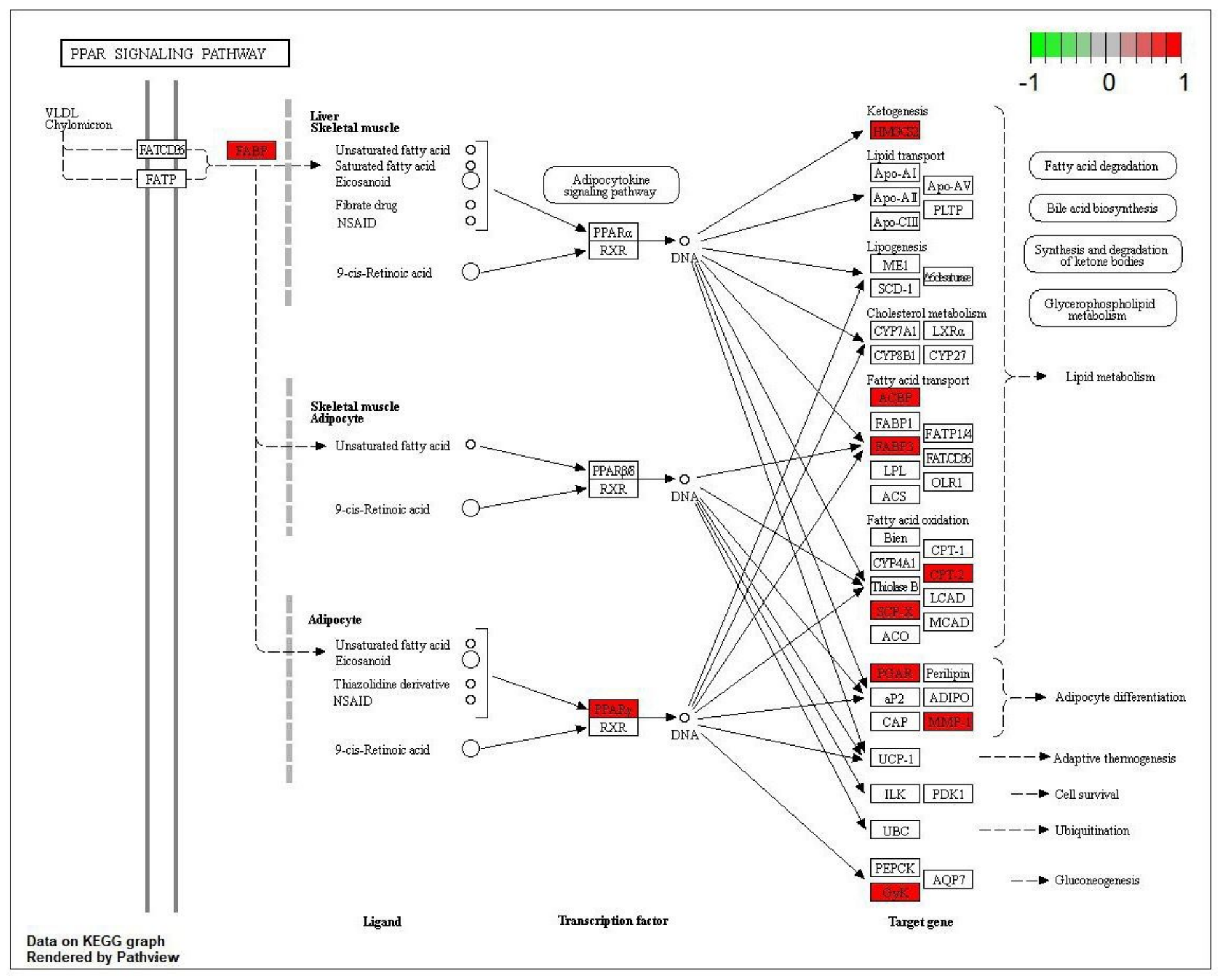

Figure 12

PPAR signaling pathway regulated by high the concentration of ciglitazone. 


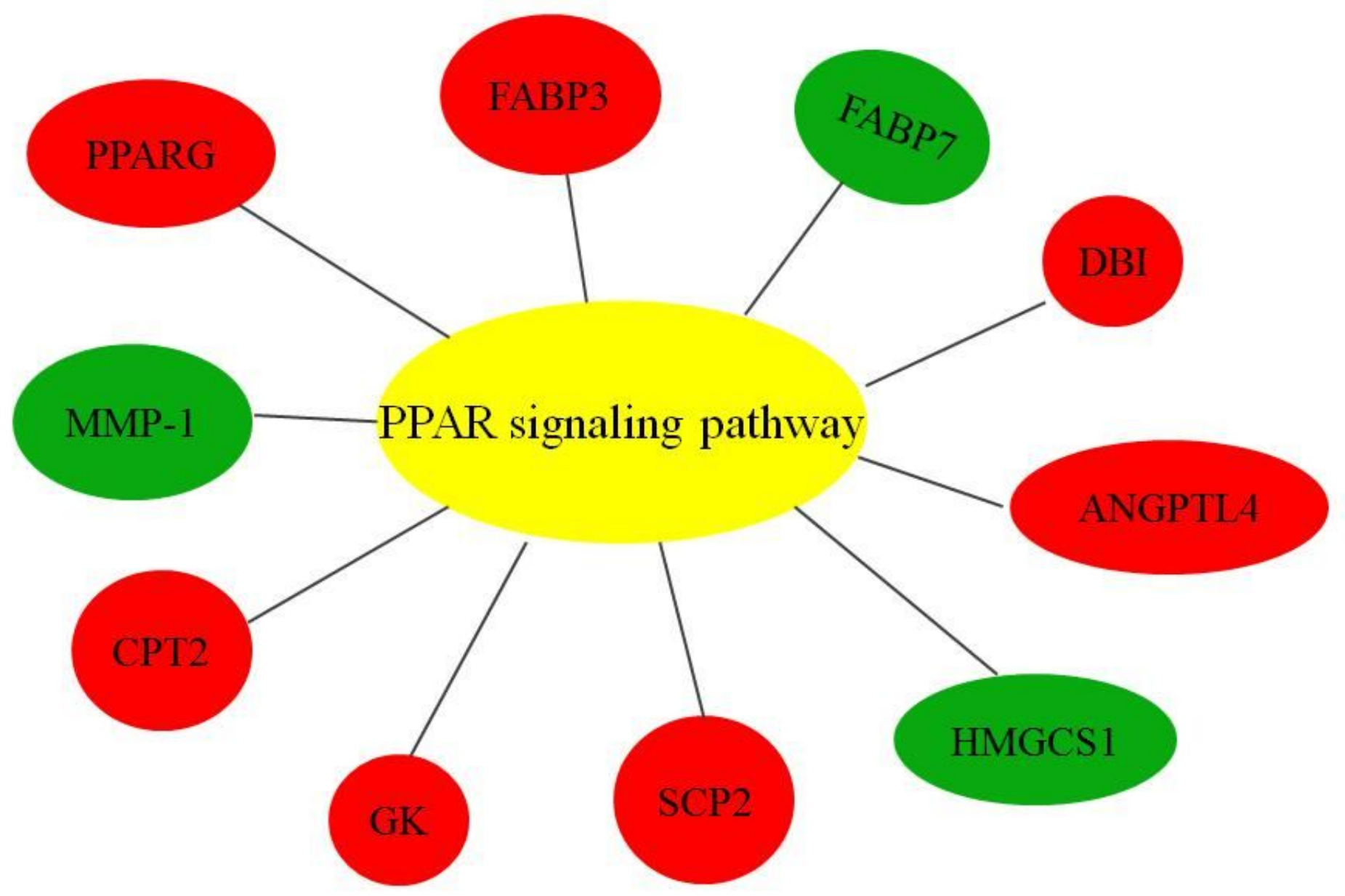

Figure 13

Distribution of up- and down-regulated genes enrichment in different Kyoto Encyclopedia of Genes and Genomes (KEGG) pathways. Pathway nodes (yellow), up-regulated genes (red), and down-regulated genes (green) are represented by circles.

\section{Supplementary Files}

This is a list of supplementary files associated with this preprint. Click to download.

- SupplementaryS1.xIsx

- SupplementaryS2.xIsx 